Document downloaded from:

http://hdl.handle.net/10251/50021

This paper must be cited as:

Espinós Capilla, A.; Gardner, L.; Romero, ML.; Hospitaler Pérez, A. (2011). Fire behaviour of concrete filled elliptical steel columns. Thin-Walled Structures. 49(2):239-255. doi:10.1016/j.tws.2010.10.008.

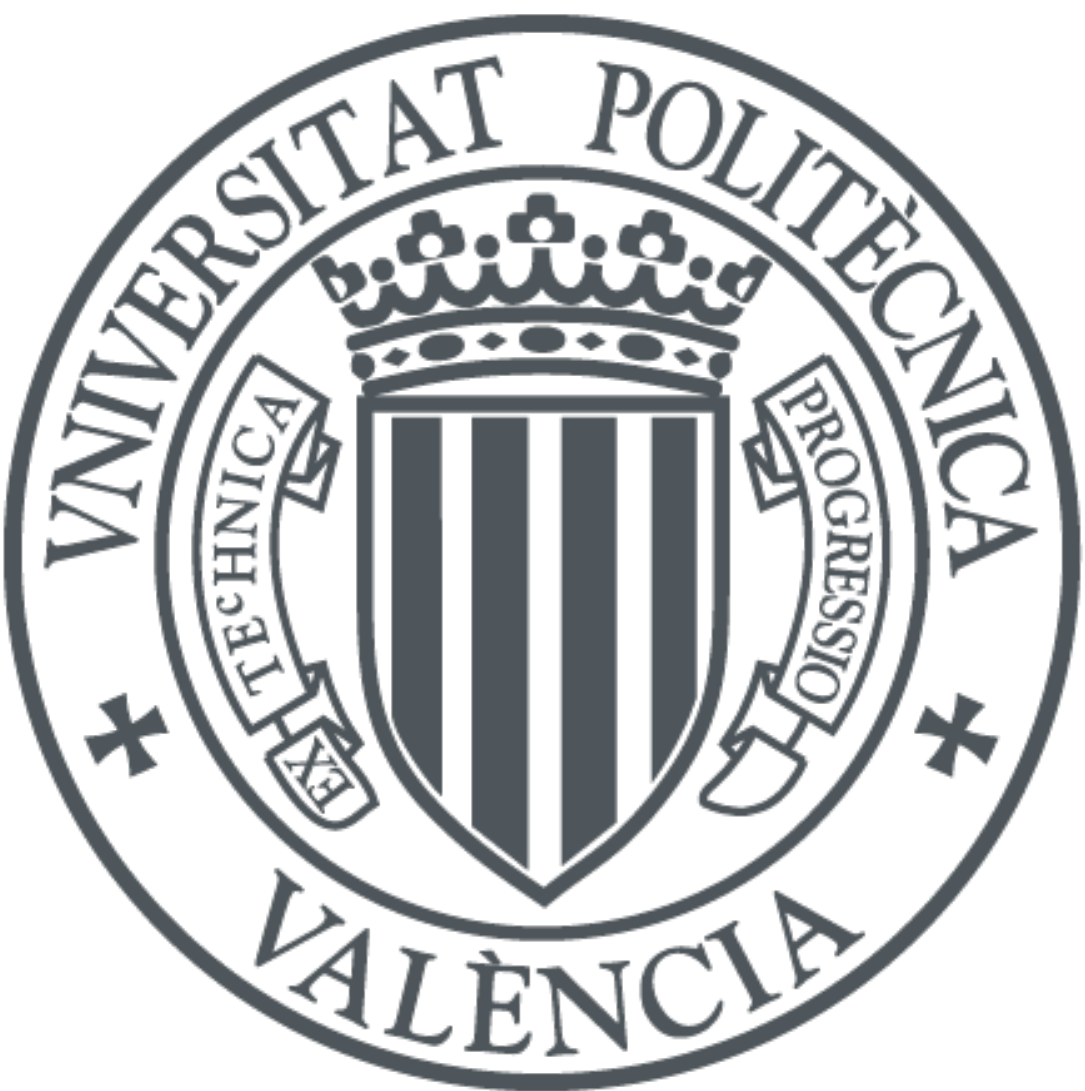

The final publication is available at

http://dx.doi.org/10.1016/j.tws.2010.10.008

Copyright Elsevier

Additional Information 


\title{
Fire behaviour of concrete filled elliptical steel columns
}

\author{
Ana Espinos ${ }^{\mathrm{a}, 1}$, Leroy Gardner ${ }^{\mathrm{b}}$, Manuel L. Romero ${ }^{\mathrm{a}, *}$, Antonio Hospitaler ${ }^{\mathrm{a}}$ \\ ${ }^{a}$ Instituto de Ciencia y Tecnología del Hormigón (ICITECH), \\ Universidad Politécnica de Valencia, Valencia, Spain \\ ${ }^{b}$ Department of Civil and Environmental Engineering, South Kensington Campus, \\ Imperial College London, London, United Kingdom \\ *Corresponding author.e-mail address: mromero@mes.upv.es \\ ${ }^{1}$ Visiting academic at Imperial College London
}

\begin{abstract}
In this work, a nonlinear three-dimensional finite element model is presented in order to study the behaviour of axially loaded concrete filled elliptical hollow section (CFEHS) columns exposed to fire. This study builds on previous work carried out by the authors on concrete filled circular hollow section (CFCHS) columns both at room temperature and in fire. The numerical model is first validated at room temperature against a series of experiments on CFEHS stub columns available in the literature and subsequently extended to study the performance of slender columns at elevated temperatures. The aim of this work is to understand and represent the behaviour of axially loaded CFEHS columns in fire situations and to compare their effectiveness with that of the circular concrete filled tubular (CFT) columns. Parametric studies to explore the influence of variation in global member slenderness, load level, cross-section slenderness and section size are presented. Finally, guidance on the fire design of CFEHS columns is proposed: it is recommended to follow the guidelines of Clause 4.3.5.1 in EN 1994-1-2, but employing the flexural stiffness reduction coefficients established in the French National Annex with an equivalent EHS diameter equal to $P / \pi$, where $P$ is the perimeter of the ellipse.
\end{abstract}


Keywords: Fire resistance; Composite columns; Concrete filled steel tubes; Elliptical hollow sections; Finite element analysis; Simple calculation model

\section{NOTATION}

$A / V \quad$ Section factor

a Half larger outer dimension of an elliptical section

$B \quad$ Outer dimension of a square section

$b \quad$ Half smaller outer dimension of an elliptical section

CFT Concrete filled tube

CFCHS Concrete filled circular hollow section

CFEHS Concrete filled elliptical hollow section

CFRHS Concrete filled rectangular hollow section

CHS Circular hollow section

$D$

Outer diameter of a circular section

EC4 Eurocode 4 Part 1-2

EHS Elliptical hollow section

FEA Finite element analysis

FEM Finite element model

FRR Fire resistance rating

$f_{c k} \quad$ Compressive cylinder strength of concrete at room temperature

$f_{c k, c u b e} \quad$ Compressive cube strength of concrete at room temperature

$f_{y} \quad$ Yield strength of structural steel at room temperature

$L \quad$ Initial length of the column

$N \quad$ Applied axial load

NF French National Annex to Eurocode 4 Part 1-2

NS Numerical simulation

$N_{f i, R d} \quad$ Design resistance of the column to axial compression in fire

$N_{f i, p l, R d} \quad$ Design plastic resistance of the column to axial compression in fire

$N_{R d} \quad$ Design resistance of the column to axial compression at room temperature

$N_{u} \quad$ Ultimate resistance of the column at room temperature

$P \quad$ Perimeter of the section

RHS Rectangular hollow section 
Espinos A, Gardner L, Romero ML, Hospitaler A. Fire behaviour of concrete filled elliptical steel columns. Thin-Walled Struct. 2011;49:239-55. doi: 10.1016/j.tws.2010.10.008

SHS

\section{$t$}

$\alpha$

$\chi$

$\varphi_{i, \theta}$

$\bar{\lambda}_{20}$

$\bar{\lambda}_{\theta}$

$\mu$

$\theta$

$\xi$

Square hollow section

Thickness of the steel tube

Imperfection factor for the buckling curves

Reduction factor for the resistance of the column in fire $\left(N_{f i, R d} / N_{f i, p l, R d}\right)$

Reduction coefficient depending on the effect of thermal stresses

Relative slenderness of the column at room temperature

Relative slenderness of the column in fire

Axial load level $\left(N / N_{R d}\right)$

Temperature

Relative error 


\section{INTRODUCTION}

The use of concrete filled tubular columns has increased in recent decades due to their excellent structural performance, which takes advantage of the combined effect of steel and concrete working together - the steel tube provides confinement to the concrete core, resulting in increased compressive strength, while the concrete core restricts inward deformation of the steel tube thus enhancing local buckling resistance and enabling the use of thinner crosssections. Circular, square and rectangular steel tubes have been traditionally used to form these composite columns. Parallel to this, a new shape of tubular section [1] has now been introduced to the construction industry: the elliptical hollow section [2]. Their aesthetic appeal and reduced visual intrusion, combined with their structural advantages associated with sections of differing major and minor axis properties, make these sections of great interest for designers [3], [4]. The structural behaviour of the elliptical sections has been deeply studied in recent years by Gardner and Chan [5] [6] [7] [8], covering cross-section classification and the evaluation of compressive, shear and bending resistances. Furthermore, the elastic buckling response of elliptical hollow sections in compression has been studied by Ruiz-Teran and Gardner [9] and Silvestre [10]. The effect of filling these columns with concrete has been examined by Yang et al. [11] and Zhao and Packer [12], through testing stub columns under compressive axial load at room temperature.

Yang et al. [11] carried out an experimental programme consisting of 21 test specimens filled with three different concrete grades (C30, C60 and C100), 15 of which were compositely-loaded, the rest being core-loaded. They found out that higher tube thickness improved the load-bearing capacity and ductility of the columns, while higher concrete strength resulted in higher load-bearing capacity but reduced ductility. Concrete shrinkage was found to have little effect on the compressive response of the columns. The confinement provided to the concrete core by the elliptical steel tubes was also assessed, finding that the 
strength and ductility of the concrete was greatly improved. Through comparing their experimental results with existing code provisions for concrete filled hollow sections, Yang et al. [11] confirmed that the behaviour of CFEHS lies between that of concrete filled circular and square/rectangular hollow sections. According to the authors, the EN 1994-1-1 [13] design expression for SHS and RHS provides an accurate and safe prediction of the compressive response of CFEHS.

Zhao and Packer [12] performed a series of tests on normal and self consolidating concrete filled elliptical hollow section stub columns with different loading methods (compositely-loaded, core-loaded and tube-loaded). The experimental load-carrying capacity of the tested specimens was compared with different code provisions. The authors proposed several design formulae, through three approaches: simple superposition of steel and concrete strengths, CFCHS approach and CFRHS approach, concluding that the existing design rules for circular and rectangular hollow section tubes are applicable to CFEHS stub columns, provided that appropriate equivalent section properties are used.

Dai and Lam [14], [15] recently developed a numerical model to represent the axial compressive behaviour of short concrete filled elliptical steel columns. They studied the differences in concrete confinement between circular and elliptical hollow sections, finding that the circular hollow sections provided higher confinement than the elliptical ones. Unlike the uniform contact stress distribution around the perimeter of circular sections, the contact forces along the perimeter of elliptical sections were non uniform, with higher stresses at the sharper corners. Based on this study, Dai and Lam [14] developed a stress-strain model for concrete confined by elliptical steel hollow sections.

Despite the room temperature behaviour of CFEHS columns being widely studied in the last few years, the performance of these columns in a fire situation has not yet been investigated, which limits their applicability in the building industry. Since there are no 
experimental results available in the literature on concrete filled elliptical hollow section columns exposed to elevated temperatures, their fire behaviour will be initially studied through numerical modelling.

The present study builds on previous research performed by the authors on concrete filled circular hollow section columns both at room temperature and in fire.

\section{VALIDATION OF THE NUMERICAL MODEL}

\subsection{Concrete filled circular hollow section columns at room temperature and exposed to fire}

Previous research on the modelling of the behaviour of concrete filled circular hollow section columns at room temperature and exposed to fire has been carried out by the authors. Firstly, the compressive resistance of both stub and slender circular CFT columns filled with different concrete grades (normal and high strength concrete) at room temperature was studied by Lacuesta et al. [16], with the models validated against experimental results obtained by Portoles et al. [17] in the testing facilities of Jaume I University (Castellón). Having established the compressive behaviour of the CFCHS columns at room temperature, their performance in fire was studied by Espinos et al. [18], where an advanced thermomechanical numerical model was developed and validated by comparing its results with a series of fire tests available in the literature. An extensive sensitivity analysis was carried out, in order to investigate the main aspects of the model, which will serve as a basis for future work on the numerical simulation of CFT columns at elevated temperatures.

A validated model for predicting the compressive resistance of CFCHS at room temperature and under fire conditions is therefore available. From this basis, the aim of the present study is to extend the existing model to the recently developed elliptical sections, in order to study their effectiveness in a fire situation when compared with circular sections. 


\subsection{Concrete filled elliptical hollow section columns at room temperature}

The compressive behaviour of CFEHS stub columns has now been well established through experimental research and numerical modelling carried out by Yang et al. [11] and Dai and Lam [14]. Nevertheless, in order to demonstrate that the model which will be developed here for studying the behaviour of CFEHS in fire is accurate, initial validation of the model at room temperature is required. For this purpose, the nine compositely loaded specimens tested by Yang et al. [11] will be utilised.

\subsubsection{Description of the finite element model}

By means of the finite element analysis package ABAQUS [19], a three-dimensional numerical model for simulating the room temperature response of CFEHS stub columns under axial compression was developed. The full length and the complete cross-section of the columns was modelled, since the experiments had revealed that in some of the cases the response was dominated by shear failure of the concrete and therefore an unsymmetrical deformed shape was expected to be obtained. Fig. 1 shows the typical finite element model adopted for this numerical investigation.

The steel tube and concrete core were meshed using three-dimensional eight-noded solid elements with reduced integration (C3D8R). Based on the results of a mesh sensitivity study, a suitable element size which provided accurate results with practical computational times was found: $5 \mathrm{~mm}$ for the steel tube and $10 \mathrm{~mm}$ for the concrete core, i.e. the concrete element size was twice the size of the steel elements.

As already found by Dai and Lam [14], two layers of elements through the thickness of the steel tube were required to accurately capture the observed experimental response. This finding is reflected in Fig. 2, where it is clear that a mesh arrangement with only one layer of 
elements through the thickness of the steel tube underestimates the load-carrying capacity of the column and fails to accurately capture the deformation history exhibited in the test.

The steel end plates were modelled as discrete rigid parts with all nodes coupled to a reference point located at the column axis. The axial load was applied to the upper rigid plate through its reference node as an imposed static displacement, transmitting load to both the concrete core and the steel tube. Following the testing procedure, all six degrees of freedom of the lower rigid plate were fixed, while the upper rigid plate was allowed to move along the column axis but was fixed against the other five degrees of freedom. The rigid plates were meshed using four-noded three-dimensional bilinear rigid quadrilateral elements (R3D4), with a maximum element size of $20 \mathrm{~mm}$.

The mechanical interaction between the contact surfaces of the steel tube and the concrete infill was modelled as follows. In the normal direction, a "hard point" contact formulation was used, which allows any pressure value when the surfaces are in contact and transmits no pressure when the surfaces do not contact. For the tangent interaction at the steelconcrete interface, the Coulomb friction model was used. It was found that values lower than 0.2 for the friction coefficient produced convergence difficulties, while values higher than 0.3 deviated from the observed response of the tested specimens. Thus, a value of 0.25 was adopted for the friction coefficient, as previously employed by Ellobody et al [20]. Moreover, Dai and Lam [14] had previously shown that the use of different friction factors had little effect on the axial resistance of CFEHS columns, and suggested that a friction factor between 0.2-0.3 would provide an accurate reflection of the actual frictional contact and achieve rapid convergence. Fig. 3 shows the effect of the friction coefficient on the compressive behaviour of the columns. The same steel-concrete mechanical interaction was employed to take into account the contact between the concrete core ends and the rigid plates. Relative displacement between the steel tube and the rigid end plates was prevented by means of a "tie" constraint. 


\subsubsection{Material models at room temperature}

For the structural steel material model, the experimental data from the coupon tests performed for each of the elliptical hollow sections under study were used. These stress-strain relationships were introduced in an isotropic multiaxial plasticity model with the Von Mises yield surface.

For concrete, the specific model developed by Dai and Lam [14] for taking into account the confinement effect in elliptical steel hollow sections was used. The model was based on that developed by other authors (Ellobody et al. [20], Mander et al. [21], Hu et al. [22] and Saenz [23]) for concrete confined by circular steel tubes. Dai and Lam [14] proposed a modified four-part stress-strain curve, with a "quick softening” section after concrete crushing based on their findings on the differences in concrete confinement between circular and elliptical hollow sections.

The yielding part of the concrete model was considered employing the Drucker-Prager yield criterion, with the values of the friction angle $(\beta)$ and flow stress ratio in triaxial tension to that in compression $(K)$ recommended by Hu et al. [22] and adopted by Ellobody et al. [20] in previous research: $\beta=20, K=0.8$. No plastic flow was considered, since the confinement effect was directly introduced to the model by means of the confined compressive stressstrain curve. Thus, a zero dilation angle $(\psi=0)$ was adopted.

\subsubsection{Comparison between numerical and experimental results}

The numerical model at room temperature was validated by comparing its results with a series of tests on concrete-filled elliptical stub columns carried out at the University of Leeds [11]. From the 21 stub columns tested, only those 9 which were compositely-loaded and nongreased were selected for this research. Those specimens were tested with full contact between the concrete infill and steel tube, and the load was applied simultaneously to the steel 
tube and concrete core. Three nominal tube thicknesses $(4 \mathrm{~mm}, 5 \mathrm{~mm}$ and $6.3 \mathrm{~mm})$ and three nominal concrete grades (C30, C60 and C100) were employed, with an elliptical section of $150 \times 75 \mathrm{~mm}$ and a length of $300 \mathrm{~mm}$, common to the nine columns. The columns analysed in this section are listed in Table 1.

For each of the nine columns analysed, the load versus end shortening response was obtained and compared with the one registered in the experimental tests. Fig. 4 shows the comparison between the numerical and experimental results for the series of columns with a $150 \times 75 \times 4 \mathrm{~mm}$ cross-section.

The numerical model showed good agreement with the tests, as can be seen in Table 2. This table compares the maximum axial compressive loads obtained from the tests with the values predicted by means of the numerical model. The error is computed as the experimental result divided by the numerical result. The maximum relative error is lower than a $5 \%$, which shows a good level of accuracy. As can be seen in the load versus end shortening curves of

Fig. 4, the agreement in terms of the overall response is also satisfactory, including capturing the softening part of the curve after reaching the maximum load. On the basis of the described comparisons, the numerical model is considered to be validated at room temperature.

\subsubsection{Findings from the finite element modelling}

A number of findings have emerged from the modelling of the CFEHS at room temperature. The mesh density study revealed that an element size of $5 \mathrm{~mm}$ for the steel tube and $10 \mathrm{~mm}$ for the concrete core should be adopted to obtain accurate results and that at least two layers of elements through the thickness of the steel tube wall should be employed.

Although the loading and boundary conditions of all the stub column specimens were symmetric, modelling the full cross-section and length of the columns revealed a more realistic response in terms of deformed shape, since it was in some cases unsymmetrical, being dominated by shear failure of the concrete core. Nevertheless, in terms of maximum 
load, the results obtained from a quarter model with symmetrical boundary conditions were similar to the full model results.

As previously found in the experiments by Yang et al. [11], two different failure patterns were observed. Fig. 5 shows these typical failure modes obtained from the numerical analysis. In some of the specimens, outward local buckling of the tube wall occurred close to the column ends (Fig. 5(a)), accompanied in some cases with a bulge at the centre of the column (Fig. 5(b)). In both cases, inward buckling of the tube wall was prevented by the concrete core. In other cases, primarily those with thinner wall thicknesses, an inclined shear failure of the concrete core was obtained (Fig. 5(c)), which is related to a loss of confinement.

As was expected and confirmed by the experimental research [11], the compressive load-bearing capacity of the columns increased both with an increase in the steel tube wall thickness and with the strength of the concrete core.

\section{BEHAVIOUR OF CONCRETE FILLED ELLIPTICAL HOLLOW SECTION COLUMNS EXPOSED TO FIRE}

Having demonstrated the ability to capture the observed response of circular CFT columns both at room temperature and in fire situations and that of the elliptical CFT columns at room temperature, it can be assumed that the numerical model will also yield accurate results for CFEHS in fire.

\subsection{Description of the finite element model}

For the analysis of the CFEHS in fire, two finite element models were needed: a thermal model and a mechanical model, since a sequentially coupled thermal-stress analysis was carried out. The steel tube and concrete core were meshed using three-dimensional eight-node heat transfer solid elements with nodal temperature degree of freedom (DC3D8) for the thermal analysis and three-dimensional eight-noded solid elements with reduced integration 
(C3D8R) in the mechanical analysis. The same mesh density as that employed for modelling the circular specimens was used for the elliptical sections, as this had proved to be sufficient to accurately predict the thermal and mechanical behaviour of CFCHS columns in fire [18]. Therefore, a maximum element size of $20 \mathrm{~mm}$ was employed for meshing both the concrete core and the steel tube. A higher mesh density would lead to unacceptable computational times for a transient thermal-stress analysis. Following the results of the numerical analysis of the stub columns at room temperature, two layers of elements through the thickness of the steel tube were employed.

The steel end plates were modelled in the same way as described in Section 2.2.1, and only used in the mechanical analysis. The columns were therefore fixed ended. The axial load was applied to the upper rigid plate through its reference node and maintained during the fire history. Owing to symmetry of both the geometry and the boundary conditions, only a quarter of the column was modelled. Since the columns analysed in this section were slender, the failure was expected to be due to global buckling, thus it was not necessary to model the entire member to account for a possible shear failure of the concrete core (which was observed in the CFEHS stub columns). Fig. 6 shows the finite element mesh for one of the CFEHS column specimens analysed.

The numerical model contained an initial geometric imperfection generated by means of the first buckling mode shape of an equivalent hinged column multiplied by an amplification factor. For this purpose, a prior eigenvalue buckling analysis was conducted. Once the initial shape of the column was obtained, it was imported to the mechanical model as the starting geometry from which to run the analysis. An amplification factor equal to the maximum imperfection along the length of the column was then applied to the column. Following the results of a sensitivity analysis carried out in previous research [18], a value of $L / 1000$ for the 
amplification factor was used. This value has also often been employed by other authors when modelling the fire behaviour of CFT columns [24].

\subsection{Material models at elevated temperatures}

The numerical simulations took into account the temperature dependent thermal and mechanical properties of steel and concrete. The adopted material models had been shown in previous research [18] to represent accurately the response of these materials in fire.

For concrete, the mechanical model developed by Lie [25] was employed, together with the hyperbolic Drucker-Prager yield surface. The thermal properties for concrete at elevated temperatures were extracted from EN 1992-1-2 [26].

For structural steel, the temperature dependent thermal and mechanical properties recommended in EN 1993-1-2 [27] were adopted. The isotropic multiaxial plasticity model with the Von Mises yield surface was employed.

The value of the thermal expansion coefficient for concrete recommended by Hong and Varma [28] was employed: $\alpha_{c}=6 \times 10^{-6}{ }^{\circ} \mathrm{C}^{-1}$. For steel, the temperature dependent values of the thermal expansion coefficient from EN 1993-1-2 [27] were adopted.

The moisture content of the concrete infill was taken into account through a peak value in the specific heat, representing the latent heat of water vaporization. A moisture content of $3 \%$ in concrete weight was considered in all cases. Hence, following the recommendations in EN 1994-1-2 [29], a specific heat peak value of $2020 \mathrm{~J} / \mathrm{kgK}$ was introduced.

\subsection{Analysis procedure}

A sequentially coupled thermal-stress analysis was used to conduct the numerical simulations, thus two different models were needed: a heat transfer model and a mechanical model. The analysis was performed by first conducting a pure heat transfer analysis for computing the temperature field and afterwards a stress/deformation analysis for calculating 
the structural response. Nodal temperatures were stored as a function of time in the heat transfer analysis results and then read into the stress analysis as a predefined field.

\subsubsection{Thermal analysis}

A nonlinear heat transfer analysis was first conducted for each of the column specimens under study. The standard ISO-834 [30] fire curve was applied to the exposed surface of the CFT column specimens as a thermal load, through the convection and radiation heat transfer mechanisms. The entire length of the columns was exposed to fire, in order to consider the worst case scenario, since protecting the column ends would introduce a higher rotational stiffness at elevated temperatures leading to a delay in the failure time. The values recommended in EN 1991-1-2 [31] were adopted for the governing parameters of the heat transfer problem.

The results from the nonlinear heat transfer analysis consisted of the temperature-time curves for all the nodes within the three-dimensional model, which were subsequently applied as a thermal load to the mechanical model.

The thermal resistance at the boundary between the steel tube and the concrete core was considered through a gap conductance value of $200 \mathrm{~W} / \mathrm{m}^{2} \mathrm{~K}$, as was used when modelling the circular specimens [18]. Moreover, the radiative heat transfer mechanism was modelled at the steel-concrete interface with emissivities of both steel and concrete surfaces equal to 0.7 and a configuration factor equal to 1 .

\subsubsection{Structural analysis}

A nonlinear stress analysis was subsequently conducted using the same FEA package [19], accounting for the nodal temperature-time curves previously calculated in the thermal model. The finite element meshes and the node numbering were exactly the same as those used in the thermal analysis model. 
In the first step, the load was applied at room temperature to the top end of the column through the loading plate. This load was maintained during the second step (the fire step), where the evolution of the temperature with the fire exposure time was imported from the thermal model.

The mechanical interaction between the steel tube and concrete infill was modelled as follows. In the normal direction, a "hard point" contact formulation was used, which allows any pressure value when the surfaces are in contact and transmits no pressure when the surfaces do not contact. For the tangent interaction, the Coulomb friction model was used, with a friction coefficient of 0.3 , though this factor had been found to have relatively little effect on the fire response of CFT columns in previous research carried out by the authors [18]. The same steel-concrete mechanical interaction was employed to model the contact between the concrete core ends and the rigid end plates. Relative displacement between the steel tube and the rigid end plates was prevented by introducing a "tie" constraint.

\subsection{Parametric studies}

The following parametric studies explore the influence of variation in global member slenderness, load level, cross-section slenderness and section size on the fire behaviour of CFEHS columns.

\subsubsection{Analysis cases}

Parametric studies were performed on the basis of a series of elliptical hollow sections of commercially available dimensions; these sections are listed in Table 3. All the analysed specimens were fixed at both ends and subjected to a concentric axial load, which was maintained during the heating step. All hollow sections had a yield strength of $355 \mathrm{MPa}$ and were filled with C30 grade concrete. The nominal elliptical section sizes employed were 150 $\times 75 \mathrm{~mm}$ and $300 \times 150 \mathrm{~mm}$. The studied thicknesses were 4,5 and $6.3 \mathrm{~mm}$ for the $150 \times 75$ 
$\mathrm{mm}$ sections and $8,10,12.5$ and $16 \mathrm{~mm}$ for the $300 \times 150 \mathrm{~mm}$ sections, in order to have a variety of cross-sectional slenderness values. The length of the column specimens was varied from 1 to 4 metres in order to cover a wide range of member slenderness values. Three different load levels were applied to each column specimen: $20 \%, 40 \%$ and $60 \%$ of their minor axis buckling resistance at room temperature. This resistance was calculated in accordance with Clause 6.7.3.5 of EN 1994-1-1 [13], employing the buckling curve "a" given in Clause 6.3.1.2 of EN 1993-1-1 [32] for hot finished hollow section columns. The applicability of this buckling curve to EHS was confirmed by Chan and Gardner [33]. The influence of enhanced concrete confinement was not considered in the room temperature resistance calculations. The material factors employed in the calculations were $\gamma_{s}=1.0$ and $\gamma_{c}$ $=1.5$ for steel and concrete respectively.

Fig. 7 shows a typical deformed column shape after fire exposure. It can be seen how overall buckling of the column is accompanied by local buckling near the column ends and a progressive opening of the gap between the steel tube and the concrete core. The temperature field at the moment of the failure of the column is plotted in this figure, where a clear radial temperature gradient can be observed.

Table 3 presents the results of all analysed column specimens. The fire resistance rating (FRR) for each column is expressed as the time measured in minutes that it is capable of sustaining the applied load before collapsing.

The period of time that a column can maintain a certain load was determined according to EN 1363-1 [34]. This standard establishes that for vertical members in compression, failure occurs when either of the following two criteria is reached:

Axial displacement limit: $L / 100 \mathrm{~mm}$

Axial displacement velocity limit: $3 L / 1000 \mathrm{~mm} / \mathrm{min}$ 
Fig. 8 shows the evolution of the axial displacement at the top end of the column against the fire exposure time, for two of the analysed columns - (a) EHS $300 \times 150 \times 10 \mathrm{~mm}, L=2 \mathrm{~m}$, $\mu=0.2$ and (b) EHS $300 \times 150 \times 10 \mathrm{~mm}, L=4 \mathrm{~m}, \mu=0.2-$. The limits given by the two failure criteria are included on the graphs.

A clear difference between the overall responses of these two columns can be observed. In Fig. 8(a), the four typical stages of the fire response of a CFT column can be easily identified: expansion of the steel tube, followed by local yielding and subsequent transfer of the applied load to the concrete core, up to the final column failure. Further explanation of this behaviour can be found in [18]. In Fig. 8(b), on the other hand, only two stages of behaviour can be identified in the fire response (expansion of the steel tube and final failure), since the column buckles before the loading plate has come back into contact with the concrete core. This effect occurs in columns with high slenderness, where failure of the column is initiated at an early stage of the fire exposure, when the steel tube is still sustaining the load without the contribution of the concrete core. Therefore, it can be inferred that the contribution of the concrete core to the load bearing capacity of the columns in a fire situation strongly depends on their slenderness.

\subsubsection{Effect of column slenderness}

It is known that the slenderness plays an important role in the buckling resistance of a column in compression. In order to illustrate the effect of the column slenderness on the fire resistance of CFEHS columns, a set of columns with fixed cross-sectional dimensions $-150 \times$ $75 \times 5 \mathrm{~mm}$ and $300 \times 150 \times 10 \mathrm{~mm}-$ were chosen. The influence of the non-dimensional slenderness was investigated by varying the column length from 1 to $4 \mathrm{~m}$ with an initial imperfection of $L / 1000$. Three different loading levels were taken into account for this study: $20 \%, 40 \%$ and $60 \%$ of the room temperature buckling resistance of the columns. 
The interrelationship between the fire resistance period of a column and its nondimensional slenderness is plotted in Fig. 9. As expected, the FRR of the columns decreased with an increase in non-dimensional slenderness. Higher load levels produced the same trend, but with lower resistance times. The FRR levels shown in Fig. 9(b) are higher than those in Fig. 9(a), since the larger the cross-section, the greater the effect of the concrete filling in delaying the temperature increase.

\subsubsection{Effect of load level}

The effect of load level on the fire resistance of CFEHS columns was studied by fixing the cross-section to $150 \times 75 \times 5 \mathrm{~mm}$ or $300 \times 150 \times 10 \mathrm{~mm}$ and the length of the column. Three loading levels were considered: $20 \%, 40 \%$ and $60 \%$ of the room temperature buckling resistance of the columns. The parametric study was repeated for four different lengths $(1,2$, 3 and $4 \mathrm{~m}$ ). The results from this analysis are plotted in Fig. 10. As expected, the fire resistance rating of the column decreased with an increase in the applied load. The drop in the fire resistance period was more abrupt for the larger columns in Fig. 10(b), which attain higher FRR values than those in Fig. 10(a), due to the higher thermal and mechanical contribution of the concrete core.

\subsubsection{Effect of cross-section slenderness}

The effect of cross-section slenderness on the fire resistance of CFEHS columns was examined by varying the thickness of the columns, while mantaining fixed external dimensions, length and loading level. The cross-section slenderness was evaluated through the parameter $D_{e} / t \varepsilon^{2}$, where $D_{e}$ is the equivalent diameter and $\varepsilon^{2}=235 / f_{y}$. The equivalent diameter was calculated according to the expression proposed by Ruiz-Teran and Gardner [9] for axial compression. 
The cross-sectional dimensions $2 a$ and $2 b$ were fixed to $300 \mathrm{~mm}$ and $150 \mathrm{~mm}$ respectively, and the thickness varied in the range of commercial values (i.e. 8, 10, 12.5 and $16 \mathrm{~mm}$ ). The length of the columns was fixed to $1 \mathrm{~m}$ and the load level to $20 \%$ of their room temperature axial compression resistance for buckling about the minor axis. The same procedure was repeated for $4 \mathrm{~m}$ length columns under the same load level. The effect of the cross-section slenderness on the fire resistance rating of the columns is illustrated in Fig. 11.

For stocky columns loaded at a low percentage of their room temperature capacity, it was found that the higher the slenderness of the steel section, the higher the fire resistance of the column, which is the case in Fig. 11(a). This means that columns with lower steel tube wall thicknesses achieve higher fire resistance for the same external dimensions. The explanation of this may reside in the fact that for a given section size, lower thicknesses of the steel tube wall allow more quantity of concrete to fill the column and thus contributing to delay its heating, which lengthens the fire resistance rating. This behaviour holds true for this particular range of columns, where the fire response is highly influenced by the amount of concrete filling, since after the expansion and subsequent yielding of the steel tube, the loading plate comes back into contact with the concrete core, which will sustain the load until the final failure.

However, the more slender columns show the inverse response: the higher the slenderness of the steel section, the lower the fire resistance of the column, as it can be seen in Fig. 11(b). This is the logical response expected for these columns, since their failure is initiated by the local buckling of the steel tube at an early stage when it is still sustaining the load without the contribution of the concrete core. The slenderness of the unfilled steel tube (and thus its thickness) is therefore a relevant factor in this case, whereas the amount of concrete filling does not influence the response. 


\subsubsection{Effect of section size}

The effect of section size was measured by means of the $A / V$ ratio (also known as section factor), where $A$ is the area of the fire exposed surface of the column per unit length and $V$ is the volume of the composite column per unit length.

From the series of columns studied, four of them with the same cross-sectional slenderness, member slenderness and loading level were selected: $75 \times 37.5 \times 2 \mathrm{~mm}$ with 0.5 m length, $150 \times 75 \times 4 \mathrm{~mm}$ with $1 \mathrm{~m}$ length, $300 \times 150 \times 8 \mathrm{~mm}$ with $2 \mathrm{~m}$ length and $600 \times$ $300 \times 16 \mathrm{~mm}$ with $4 \mathrm{~m}$ length. The procedure was repeated for three loading levels: $20 \%$, $40 \%$ and $60 \%$ of their room temperature buckling resistance. The interrelationship between the fire resistance period of a column and its section factor is plotted in Fig. 12.

A column with a high $A / V$ ratio exposes a relatively high surface to the fire, heating up faster, while a column with a low $A / V$ ratio exposes a lower surface to the fire for the same volume, thus delaying its heating. Therefore, as expected, the columns with the higher $A / V$ ratios had a lower fire resistance period than those with low $A / V$ ratios. The same trend was followed for all three load levels, but was steeper for the lower one. From Fig. 12, it can be concluded that for high $A / V$ ratios, the effect of a change in the load level is minor. Conversely, for columns with a low $A / V$ ratio, an important difference in terms of fire resistance can be found under different load levels.

\section{DISCUSSION AND DESIGN RECOMMENDATIONS}

\subsection{Comparison between elliptical and circular concrete filled columns in fire}

In order to study the differences in fire performance between CFEHS columns and CFCHS columns, a series of circular sections equivalent to the elliptical sections previously analysed were numerically examined. 
The circular columns were designed to have the same buckling resistance at room temperature as the corresponding elliptical columns, whilst maintaining the same length. This was selected for practical purposes, in order to serve as a reference to designers when having to choose between circular and elliptical sections for a given inter-storey height and design load. The diameters of the circular sections were determined by fixing the thickness of the steel tube to be the same as that of the elliptical sections. The main characteristics of the circular columns analysed in this research are listed in Table 4, together with the fire resistance rating obtained from the numerical model for the three different loading levels under consideration.

Through the numerical analysis of the equivalent circular columns and its comparison with the previously calculated elliptical columns it was observed that the CFCHS achieved in general higher fire resistance than the equivalent CFEHS, due to the lower $A / V$ ratio of the circular columns for a same room temperature resistance. This results in a delay in the temperature field evolution and thus an increase in fire resistance rating. Only for the $150 \times$ $75 \times 5 \mathrm{~mm}$ of $4 \mathrm{~m}$ length did the elliptical column resist longer than the circular column, due to the fact that, for this particular column, the $A / V$ ratio of the elliptical column was lower than that of its equivalent circular column.

This effect can easily be noticed if the temperature field of the elliptical and its equivalent circular section are compared for the same fire exposure time. Fig. 13 shows the resulting cross-sectional temperature fields for an elliptical column and its equivalent circular column after 90 minutes of exposure to fire. It can be seen that for the same exposure time, and thus a similar temperature at the steel surface, the temperatures along the concrete core are higher in the elliptical column than in the circular. This is due to the higher $A / V$ ratio of the elliptical column, which exposes more surface to the fire for the same cross-section, and therefore heats up faster. This effect can be clearly seen in Fig. 14, where the temperature 
evolution along the cross-section is compared for different fire exposure times. The relative distance to the centre of the column is expressed as the distance from a particular point of the cross-section to its centre, divided by the radius.

In terms of fire resistance rating, a comparison is shown in Fig. 15 between circular and elliptical columns with different lengths and load levels. It can be seen that the circular columns attain higher fire resistance ratings than their elliptical counterparts; the difference is more pronounced for the stocky columns and for low loading levels. As the length and therefore the slenderness of the column increases, the difference in fire performance between elliptical and circular shapes is not so clear for the $150 \times 75 \times 5 \mathrm{~mm}$ columns, since the failure is due to yielding of the steel tube wall followed by global buckling before the concrete core comes back into contact with the loading plate, and thus the section shape and its related temperature distribution within the cross-section have less influence over the response of the columns. This aspect can also be appreciated in the larger columns $(300 \times 150 \times 10 \mathrm{~mm})$ for load levels of 0.4 and 0.6 , where the difference is clearly narrower than for a load level of 0.2 . The explanation resides in the fact that for these high load magnitudes the sectional effects are of less importance since the severity of the load limits the temperature development within the cross-section and hence the sectional shape and its effect on the thermal distribution is not crucial.

For the set of columns compared in this research, the average improvement in fire resistance achieved by the circular columns over the elliptical columns was about $20 \%$, with less use of steel in all cases (6\% less on average) and a similar volume of concrete, except for columns $150 \times 75 \times 5 \mathrm{~mm}$ with 3 and $4 \mathrm{~m}$ length, where the amount of concrete was considerably reduced in the circular columns. It is worth noting that the comparison was carried out by considering buckling of the elliptical columns about their minor axis. Therefore, for the same length and load bearing capacity at room temperature, the slenderness 
of the elliptical columns was higher than that of the circular ones, which is magnified when exposed to fire (due to the different rate of loss of strength and stiffness with temperature) and explains the high differences encountered in some cases even when the amount of material employed in the circular columns was lower.

\subsection{Simple calculation models for concrete filled elliptical hollow section columns in fire}

\subsubsection{Discussion of existing design guidance}

The fire behaviour of concrete filled elliptical hollow sections is not explicitly covered in existing design codes. EN 1994-1-2 [29] covers concrete encased and partially encased steel columns as well as unprotected concrete filled hollow sections. Clause 4.3.5.1 describes a simple calculation model for composite columns in general, while Annex G and Annex $\mathrm{H}$ give specific methods for steel sections with partial concrete encasement and unprotected concrete filled hollow sections, respectively.

Despite there being no reference to concrete filled tubes of elliptical shape in the current version of EN 1994-1-2 [29], application of the simple calculation model for concrete filled hollow section columns to the elliptical tubes is considered in this paper. The design procedure of Clause 4.3.5.1 in EN 1994-1-2 [29] is described below.

The design value of the resistance of composite columns in axial compression exposed to fire is calculated as:

$N_{f i, R d}=\chi N_{f i, p l, R d}$

where $\chi$ is the reduction coefficient for buckling curve "c" given in Clause 6.3.1.2 of EN 1993-1-1 [32] (obtained from the value of the relative slenderness at elevated temperature) and $N_{f i, p l, R d}$ is the design value of the plastic resistance to axial compression in fire.

The design value of the plastic resistance of the column in fire, considering that it has no reinforcement, is given by: 


$$
N_{f i, p l, R d}=\sum_{j}\left(A_{a, \theta} f_{a y, \theta}\right) / \gamma_{M, f i, a}+\sum_{m}\left(A_{c, \theta} f_{c, \theta}\right) / \gamma_{M, f i, c}
$$

where $\mathrm{A}_{i, \theta}$ is the area of each element of the cross-section to which a certain temperature $\theta$ is attributed and subscripts " $a$ " and " $c$ " refer to the steel profile and concrete, respectively.

The effective flexural stiffness of the column can be calculated through:

$$
(E I)_{f i, e f f}=\sum_{j}\left(\varphi_{a, \theta} E_{a, \theta} I_{a, \theta}\right)+\sum_{m}\left(\varphi_{c, \theta} E_{c, \mathrm{sec}, \theta} I_{c, \theta}\right)
$$

where $I_{i, \theta}$ is the second moment of area of each element of the cross-section to which a certain temperature $\theta$ is attributed, $\varphi_{i, \theta}$ is a reduction coefficient depending on the effect of thermal stresses and $E_{c, s e c, \theta}$ is the secant modulus of concrete at a temperature $\theta$. For partially encased steel sections, the reduction coefficients have been defined in Annex G. However, for concrete filled sections these reduction coefficients have yet to be established; in the absence of predefined values a common approach in practice is to take them as equal to unity [35].

The Euler buckling load in a fire situation is calculated as:

$N_{f i, c r}=\pi^{2}(E I)_{f i, e f f} / \ell_{\theta}^{2}$

where $\ell_{\theta}$ is the buckling length of the column at a certain temperature $\theta$.

The relative slenderness of the column at elevated temperatures is given by:

$$
\bar{\lambda}_{\theta}=\sqrt{N_{f i, p l, R} / N_{f i, c r}}
$$

where $N_{f i, p l, R}$ is the value of $N_{f i, p l, R d}$ when the material factors are taken as 1.0. This value of the relative slenderness is used to enter to the buckling curve "c", from where the reduction coefficient needed for determining the buckling load is obtained.

In addition to the approach described above, Annex H (informative) of EN 1994-1-2 [29] provides a simple calculation model specifically for concrete filled hollow sections in fire. It establishes that the design axial buckling load can be obtained from the equilibrium equation: 


$$
N_{f i, R d}=N_{f i, c r}=N_{f i, p l, R d}
$$

The procedure is based on increasing the strain in steps until $N_{f i, c r}$ and $N_{f i, p l, R d}$ are equal, subjected to the condition that the axial strain of all the components of the cross-section is the same. The instantaneous values of the stress and tangent modulus of each material for a particular temperature are used, varying with the strain level. In this approach, the reduction coefficients to account for the thermal stresses are not used.

Recently, Leskela [36] and Aribert et al. [37] have highlighted several shortcomings of Annex $\mathrm{H}$, which at present is under revision. While a new specific simplified model for concrete filled columns in fire is developed, it seems that following the general principles of Clause 4.3.5.1 is more appropriate. However, as the values of the reduction coefficients to account for the effect of thermal stresses are not given in EN 1994-1-2 [29] for concrete filled columns, some assumptions must be adopted for their treatment.

These flexural stiffness reduction coefficients were introduced into the simple calculation model to account for the effect of the thermal stresses caused by the non-uniform temperature distribution within a composite cross-section and the unequal thermal expansion of steel and concrete [35]. This leads to a non-uniform thermal and thus mechanical strain distribution and since the stress-strain curves of the materials are non-linear, it results into a redistribution of stiffness across the composite section, different from that based on assuming a uniform strain distribution.

As a first approach (hereafter referred to as EC4(1)), the reduction coefficients were taken as unity, which means neglecting the effect of the thermal stresses. In a second approach (hereafter referred to as EC4(2)), the values proposed by Aribert et al. [37] for the reduction coefficients were adopted. These values are a result of an extensive parametric investigation carried out at the CTICM (Centre Technique Industriel de la Construction Métallique) [38] and are currently normative in France, having been included in the French 
National Annex to EN 1994-1-2 (NF EN 1994-1-2/NA) [39]. For the concrete core, a reduction coefficient of 0.8 is specified, resulting in $\varphi_{c, \theta}=1.2$, which includes implicitly the use of the initial tangent modulus of concrete (calculated as $3 / 2$ times the secant modulus, therefore $0.8 \times 3 / 2=1.2$ for direct application over the secant modulus), while for the steel hollow section the value of the reduction coefficient $\varphi_{a, \theta}$ depends on the fire duration and the size $(B$ or $D)$ of the steel section, according to Table 5, taken from Clause 4(2) of NF EN 1994-1-2/NA. The rest of the procedure used in this second approach followed the general flow chart of Clause 4.3.5.1 in EN 1994-1-2, employing as recommended buckling curve "c".

Finally, the complete method described in NF EN 1994-1-2/NA [39] (hereafter referred to as EC4(NF)) was applied and included in this study. The method included in the French National Annex, apart from accounting for the effect of the differential thermal stresses within the composite column cross-section through the reduction coefficients, establishes specific buckling curves with a discontinuity at a certain value of the relative slenderness, called the "transition relative slenderness". This transition value is dependent on the fire exposure time, and is equal to 1.0 for R30 and 1.35 for R60 in the case of unreinforced columns. Before reaching the transition value, the buckling curve follows the shape of the EN 1993-1-1 [32] curves but with a different imperfection factor for the different fire periods ( $\alpha=0.21$ for R30 and $\alpha=0.265$ for R60). For relative slenderness values above the transition slenderness, the method employs a buckling curve of the form:

$\chi\left(\bar{\lambda}_{\theta}\right)=\beta\left(\bar{\lambda}_{\theta}\right)^{-\gamma}$

with non-dimensional coefficients $\beta$ and $\gamma$ as a function of the sectional dimensions.

Since the French proposal is specific to circular and square columns, not considering different dimensions in the two axes, for entering to Table 2 in NF EN 1994-1-2/NA (Table 5 in this paper) an equivalent diameter has to be defined in order to apply the method to the elliptical columns. 
It can be thought that the temperature field of a CFEHS lies between that of the CFCHS of diameter equal to $2 a$ and $2 b$. This can be confirmed by comparing the temperature distributions of these columns, which is represented in Fig. 16. It can be seen that the thermal gradient within the elliptical cross-section lies between that of the circular cross-sections of diameter equal to $2 a$ (higher gradient) and $2 b$ (lower gradient) for a particular exposure time. An intermediate equivalent diameter, between $2 a$ and $2 b$ should be therefore adopted for entering to Table 2 in NF EN 1994-1-2/NA. As a first approximation, a value of $P / \pi$ (i.e. the diameter of that circle which has the same perimeter than the elliptical section) is adopted.

The three different approaches outlined above were applied to a series of circular and elliptical concrete filled columns listed in Table 6 and Table 7 respectively. In these tables Clause 4.3.5.1 of EN 1994-1-2 with coefficients $\varphi_{i, \theta}$ equal to unity and buckling curve "c" is referred to as EC4(1), the same procedure with coefficients proposed by Aribert et al. [37] is referred to as EC4(2) and NF EN 1994-1-2/NA is referred to as EC4(NF).

As an initial step, the cross-sectional temperature field of each column was obtained by means of the finite element model previously described in this paper. Once the temperature field had been established, the cross-section was divided into a number of concentric circular or elliptical layers, and each of these layers was assigned a representative temperature. The structural behaviour of the columns was then evaluated through the application of the reduction coefficients of strength and stiffness corresponding to each layer for a particular exposure time, according to the corresponding code provisions.

The errors in terms of buckling load obtained with reference to the numerical results by applying these different design approaches are included in Table 6 for CFCHS columns and Table 7 for CFEHS columns. The buckling loads were obtained in all cases by taking the temperature field at the time of failure from the numerical analysis and assuming a buckling length equal to 0.5 times the length of the column in the application of the code, 
corresponding to columns located in an intermediate storey of a building as per Clause 4.3.5.1(10) of EN 1994-1-2 [29].

Fig. 17 shows the results obtained from the three approaches for CFCHS columns, expressed in terms of difference between code predictions and numerical model against the relative slenderness of the columns at room temperature. Fig. 18 shows the corresponding results for CFEHS columns, having assumed an equivalent diameter of $P / \pi$ for applying the French reduction coefficients.

The first approach, where the reduction coefficients were taken as equal to unity, clearly produced unsafe results for room temperature relative slenderness values over 0.4 , which can be seen in Fig. 17 and Fig. 18. This finding confirms the conclusions obtained in previous research by the authors [18], and proves to be also valid for elliptical columns. The average value of the error in buckling load was higher than unity for both circular (Table 6) and elliptical columns (Table 7), indicating unsafe results. This effect was more noticeable for the elliptical columns. In turn, the second approach, employing the French National Annex coefficients combined with buckling curve "c", generally produced safe results for the full range of slenderness studied (with average values lower than unity in Table 6 and Table 7). The results obtained by means of NF EN 1994-1-2/NA are also included in the tables and in Fig. 17 and Fig. 18. This method also produced conservative results, with an average error closer to unity in Table 6 and Table 7, although with more scattered predictions. Unsafe values were obtained in a number of cases. The resulting average value was closer to the numerical predictions for the circular columns than for the elliptical columns, where the difference in accuracy between EC4(2) and EC4(NF) approaches is not so clear. It is worth noting that the French method is limited to a minimum dimension of $100 \mathrm{~mm}$ and a maximum fire resistance of 60 minutes for unreinforced columns, which puts some of the specimens under study outside the limits of applicability. 
In order to investigate further the differences caused by the reduction coefficients to account for the thermal stresses and have a basis to develop future design recommendations for elliptical columns, the numerical results expressed in terms of normalised resistance (relative to the plastic resistance to axial compression in fire) are plotted against the relative slenderness at the time of failure of the columns in Fig. 19 (considering the reduction coefficients equal to unity) and Fig. 20 (adopting the values for the reduction coefficients proposed by Aribert et al. [37]). The EN 1993-1-1 [32] buckling curve "c" has been superimposed onto both graphs for comparison purposes.

Fig. 19 shows that when neglecting the reduction coefficients, the results are generally over-predicted by buckling curve "c" for both circular and elliptical columns, except for the stockier ones, which are under-predicted. This result for stocky columns means that in the numerical simulations these columns showed higher load bearing capacity than their computed plastic resistance in fire, which is attributed to the confinement effect of the steel tube which increases the load bearing capacity of the composite section and is not accounted for in the plastic resistance calculation. Most of the points, however, lie below the buckling curve "c", which means that when employing this curve with the general flow chart for design, the results obtained would be unsafe.

It therefore seems that neglecting the effect of the thermal stresses when applying the simple calculation model results in clear deviation from the actual buckling response of the columns. It can be observed in Fig. 19 that this difference with reference to buckling curve "c" is larger for the more slender columns. This can be explained as follows: for both short and long columns, the thermal stresses are the same for a certain restraint level and temperature field (since they are caused by thermal strains which are only a function of temperature). However, in long columns the applied stress levels required to cause buckling are lower than for short columns, so the thermal stresses are a higher proportion of the total 
stress and therefore have a greater influence in the buckling response at elevated temperatures. To sum up, the effect of the thermal stresses is more noticeable for slender columns and therefore has to be carefully taken into account when calculating their buckling resistance in fire.

When the flexural stiffness reduction coefficients proposed by Aribert et al. [37] are adopted, the majority of the points lie above the buckling curve "c", as can be seen in Fig. 20 for both circular and elliptical columns, which means that it can be safely applied to compute the column buckling resistance in fire. It seems therefore that this approach is the one to follow when one wants to apply the general flow chart of Clause 4.3.5.1 in EN 1994-1-2, although a better fitted curve could be developed in order to obtain more accurate predictions of fire resistance.

\subsubsection{Recommendations for design guidance of elliptical columns}

Following the previous discussion of the existing design guidance, it can be concluded that, in the absence of predefined values for the reduction coefficients to account for the effect of thermal stresses in concrete filled columns, employing the coefficients proposed by Aribert et al. [37] is acceptable, producing conservative results when used in combination with the buckling curve "c". The NF EN 1994-1-2/NA [39] simple calculation model, which uses these same coefficients but with revised buckling curves, generally produces conservative results, with a better average prediction, but with a higher dispersion of results.

Hence, for CFEHS columns, it is recommended that the flexural stiffness reduction coefficients are obtained from the French National Annex, using an equivalent diameter $D=$ $P / \pi$ when applying the tabulated data. It is then proposed to follow the guidelines of the simple calculation model of Clause 4.3.5.1 in EN 1994-1-2 [29], employing buckling curve “c", this proposal being valid for both circular and elliptical columns. The NF EN 1994-12/NA [39] simple calculation model can be applied as an alternative for calculating the fire 
resistance of CFT columns, although a wider study should be conducted to confirm its validity for elliptical sections.

\section{SUMMARY AND CONCLUSIONS}

The fire response of concrete filled elliptical hollow section columns has been studied in this paper through finite element modelling. The numerical model had previously been validated for concrete filled circular columns exposed to fire and, in the absence of fire tests on elliptical columns, the values of the modelling parameters previously obtained from the circular column sensitivity analysis were employed. As further validation, the response of concrete filled elliptical stub columns at room temperature was studied by means of the numerical model and compared with test results. The model showed good agreement with the tests, indicating that it is capable of representing the composite behaviour between the steel and concrete in elliptical sections. Having obtained a good representation of the room temperature interaction for elliptical columns, the behaviour at elevated temperatures was studied. Parametric studies were conducted in order to assess the influence of the column slenderness, load level, cross-section slenderness and section size on the fire response of the concrete filled elliptical columns. As expected, the fire resistance of the columns decreases with an increase in member slenderness and load level, as well as with an increase of the section factor $(A / V$ ratio). The influence of cross-section slenderness and section thickness is not so clear, with opposing trends obtained for stocky and slender columns, which is related to their different failure modes.

A comparative study between elliptical and circular concrete filled hollow section columns in fire has also been presented. This study has shown that for a certain column length and load bearing capacity at room temperature, the circular columns attain higher fire resistance than the elliptical columns, with reduced material use. This is due to the lower $A / V$ ratio that the circular sections present, which delays the heating up of the column therefore 
providing a longer fire resistance period. The difference in performance between elliptical and circular columns is less evident for slender columns, since the sectional effects have a lower influence. These conclusions are only valid for centrally loaded columns under axial compression, since for eccentric loads the elliptical shapes would provide more efficient structural performance than the circular sections if the load is aligned such that it generates a bending moment about the major axis. The differences in fire behaviour under eccentric loads therefore require a wider study, which will be addressed in future work.

Finally, a review of existing design guidance for the calculation of the buckling resistance of concrete filled columns in fire has been carried out. In the absence of guidance on the flexural stiffness reduction coefficients to account for the effect of thermal stresses in concrete filled columns in EN 1994-1-2, a number of alternative values were assumed. This study showed that assuming these coefficients are equal to unity (i.e. neglecting the effect of the differential thermal stresses) gives rise to unsafe results when applying the EN 1994-1-2 simple calculation model for columns with room temperature relative slenderness over 0.4 ; this was observed for both circular and elliptical shapes. However, assuming the reduction coefficients proposed in the French National Annex to EN 1994-1-2 in combination with buckling curve "c", safe results are achieved. It is recommended that the general flow chart in Clause 4.3.5.1 of EN 1994-1-2 with the flexural stiffness reduction coefficients taken from the French National Annex using an equivalent diameter of $D=P / \pi$ is adopted for elliptical columns.

\section{ACKNOWLEDGEMENTS}

The authors would like to express their sincere gratitude to the Spanish "Ministerio de Ciencia e Innovación" for the help provided through the Project BIA2009-9411 and to the European Union through the FEDER funds. 
The authors would also like to acknowledge Universidad Politécnica de Valencia for providing fellowship funding for the first author's stay as a visiting academic at Imperial College London.

\section{REFERENCES}

[1] CEN. EN 10210-2. Hot finished structural hollow sections of non-alloy and fine grain steels. Part 2: Tolerances, dimensions and sectional properties. Brussels, Belgium: Comité Européen de Normalisation; 2006.

[2] Corus. Celsius 355 Ovals - Sizes and Capacities, EC3 Version. Corus Tubes - Structural \& conveyance business; 2007

[3] Gardner L, Ministro A. Structural steel oval hollow sections. Structural Engineer 2005; 83(21):32-36.

[4] Packer JA. Going elliptical. Modern Steel Construction 2008; 48(3):65-67.

[5] Chan TM, Gardner L. Compressive resistance of hot-rolled elliptical hollow sections. Engineering Structures 2008; 30(2):522-532.

[6] Chan TM, Gardner L. Bending strength of hot-rolled elliptical hollow sections. Journal of Constructional Steel Research 2008; 64(9):971-986.

[7] Gardner L, Chan TM, Wadee MA. Shear response of elliptical hollow sections. Proceedings of the Institution of Civil Engineers - Structures and Buildings 2008; 161(6):301-309

[8] Gardner L, Chan TM. Cross-section classification of elliptical hollow sections. Steel and Composite Structures 2007; 7(3):185-200.

[9] Ruiz-Teran AM, Gardner L. Elastic buckling of elliptical tubes. Thin-Walled Structures 2008; 46(11):1304-1318. 
[10] Silvestre N. Buckling behaviour of elliptical cylindrical shells and tubes under compression. International Journal of Solids and Structures 2008; 45(16):4427-4447.

[11] Yang H, Lam D, Gardner L. Testing and analysis of concrete-filled elliptical hollow sections. Engineering Structures 2008; 30:3771-3781.

[12] Zhao XL, Packer JA. Tests and design of concrete-filled elliptical hollow section stub columns. Thin-Walled Structures 2009; 47:617-628.

[13] CEN. EN 1994-1-1, Eurocode 4: Design of composite steel and concrete structures. Part 1-1: General rules and rules for buildings. Brussels, Belgium: Comité Européen de Normalisation; 2004.

[14] Dai X, Lam D. Numerical modelling of the axial compressive behaviour of short concrete-filled elliptical steel columns. Journal of Constructional Steel Research 2010; 66:931-942.

[15] Lam D, Dai X. Modelling the confinement effect of composite concrete-filled elliptical steel columns. In: Proceedings of the Sixth International Conference on Advances in Steel Structures, p. 49-62. Hong Kong, China: The Hong Kong Institute of Steel Construction; 2009.

[16] Lacuesta C, Romero ML, Ivorra S, Portoles JM. A three-dimensional numerical model of circular concrete filled columns. In: Proceedings of the Eighth International Conference on Computational Structures Technology. Stirlingshire, UK: B.H.V. Topping, G. Montero, R. Montenegro (Editors); 2006. Paper 22, doi:10.4203/ccp.83.22.

[17] Portoles JM, Romero ML, Bonet JL, Filippou FC. Experimental study of high strength concrete-filled circular tubular columns under eccentric loading. Journal of Constructional Steel Research 2010 (submitted for evaluation). 
[18] Espinos A, Romero ML, Hospitaler A. Advanced model for predicting the fire response of concrete filled tubular columns. Journal of Constructional Steel Research 2010; 66:1030-1046.

[19] ABAQUS. ABAQUS/Standard Version 6.6 User's Manual: Volumes I-III. Pawtucket, Rhode Island: Hibbit, Karlsson \& Sorenson, Inc.; 2005.

[20] Ellobody E, Young B, Lam D. Behaviour of normal and high strength concrete-filled compact steel tube circular stub columns. Journal of Constructional Steel Research 2006; 62:706-715.

[21] Mander JB, Priestley MJN, Park R. Theoretical stress-strain model for confined concrete. ASCE Journal of Structural Engineering 1988; 114(8):1804-1826.

[22] Hu HT, Huang CS, Wu MH, Wu YM. Nonlinear analysis of axially loaded concretefilled tube columns with confinement effect. ASCE Journal of Structural Engineering 2003; 129(10):1322-1329.

[23] Saenz LP. Discussion of 'Equation for the stress-strain curve of concrete' by P. Desayi, and S. Krishnan. Journal of the American Concrete Institute 1964; 61:1229-1235.

[24] Ding J, Wang YC. Realistic modelling of thermal and structural behaviour of unprotected concrete filled tubular columns in fire. Journal of Constructional Steel Research 2008; 64:1086-1102.

[25] Lie TT. Fire resistance of circular steel columns filled with bar-reinforced concrete. ASCE Journal of Structural Engineering 1994; 120(5):1489-1509.

[26] CEN. EN 1992-1-2, Eurocode 2: Design of concrete structures. Part 1-2: General rules Structural fire design. Brussels, Belgium: Comité Européen de Normalisation; 2004.

[27] CEN. EN 1993-1-2, Eurocode 3: Design of steel structures. Part 1-2: General rules Structural fire design. Brussels, Belgium: Comité Européen de Normalisation; 2005. 
[28] Hong S, Varma AH. Analytical modeling of the standard fire behavior of loaded CFT columns. Journal of Constructional Steel Research 2009; 65:54-69.

[29] CEN. EN 1994-1-2, Eurocode 4: Design of composite steel and concrete structures. Part 1-2: General rules - Structural fire design. Brussels, Belgium: Comité Européen de Normalisation; 2005.

[30] ISO (International Standards Organization). ISO 834: Fire resistance tests, elements of building construction. Switzerland: International Standards Organisation; 1980.

[31] CEN. EN 1991-1-2, Eurocode 1: Actions on structures. Part 1-2: General actions Actions on structures exposed to fire. Brussels, Belgium: Comité Européen de Normalisation; 2002.

[32] CEN. EN 1993-1-1, Eurocode 3: Design of steel structures. Part 1-1: General rules and rules for buildings. Brussels, Belgium: Comité Européen de Normalisation; 2005.

[33] Chan TM, Gardner L. Flexural buckling of elliptical hollow section columns. ASCE Journal of Structural Engineering 2009; 135:546-557.

[34] CEN. EN 1363-1: Fire resistance tests. Part 1: General requirements. Brussels, Belgium: Comité Européen de Normalisation; 1999.

[35] Lennon T, Moore DB, Wang YC, Bailey CG. Designers' guide to EN 1991-1-2, EN 1992-1-2, EN 1993-1-2 and EN 1994-1-2. Thomas Telford Limited; 2007.

[36] Leskela MV. Inconsistencies in the fire design rules of composite columns to EN 1994-12. Steel Concrete Composite and Hybrid Structures, pp. 489-494. Leeds, England; 2009.

[37] Aribert JM, Renaud C, Zhao B. Simplified fire design for composite hollow-section columns. Structures \& Buildings 2008; 161:325-336.

[38] Renaud C, Joyeux D, Kruppa J. Improvement and extension of the simple calculation method for fire resistance of unprotected concrete filled hollow columns. CIDECT 
Espinos A, Gardner L, Romero ML, Hospitaler A. Fire behaviour of concrete filled elliptical steel columns. Thin-Walled Struct. 2011;49:239-55. doi: 10.1016/j.tws.2010.10.008

Research Project 15Q-12/03. Saint-Rémy-lès-Chevreuse Cedex, France: Centre Technique Industriel de la Construction Métallique (CTICM); 2004.

[39] AFNOR. Calcul simplifié de la résistance au feu des profils creux remplis de béton exposés aux conditions d'incendie normalisé. Annexe PCRB, pp. 9-16, NF-EN 1994-12/NA. Paris, France: Association Française de Normalisation; 2007. 
Espinos A, Gardner L, Romero ML, Hospitaler A. Fire behaviour of concrete filled elliptical steel columns. Thin-Walled Struct. 2011;49:239-55. doi: 10.1016/j.tws.2010.10.008

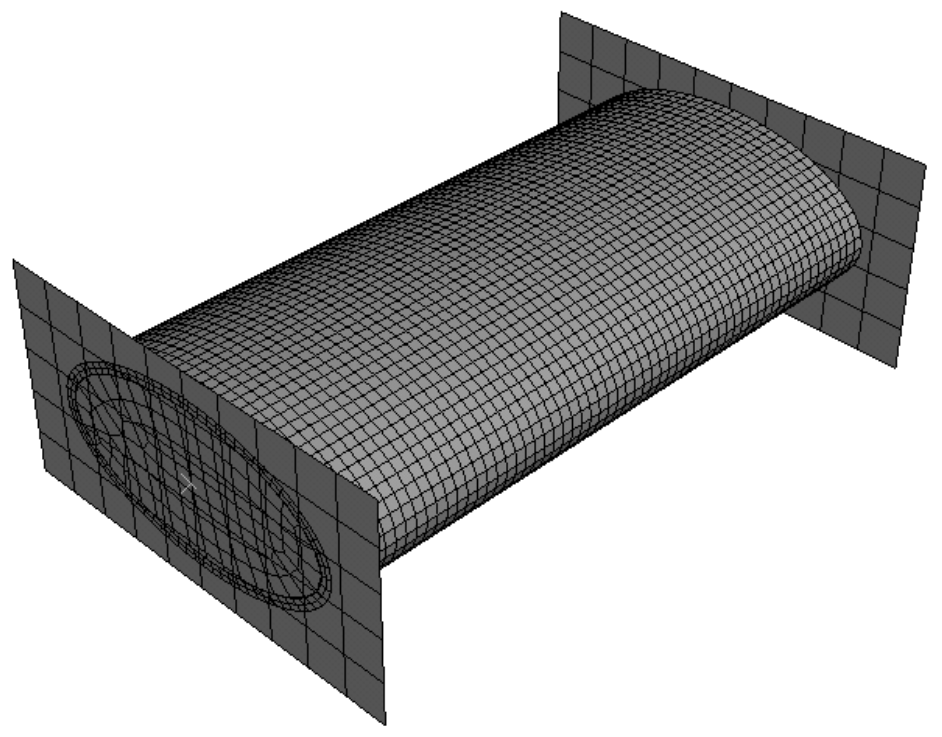

Fig. 1. Three-dimensional finite element model for CFEHS stub columns. 


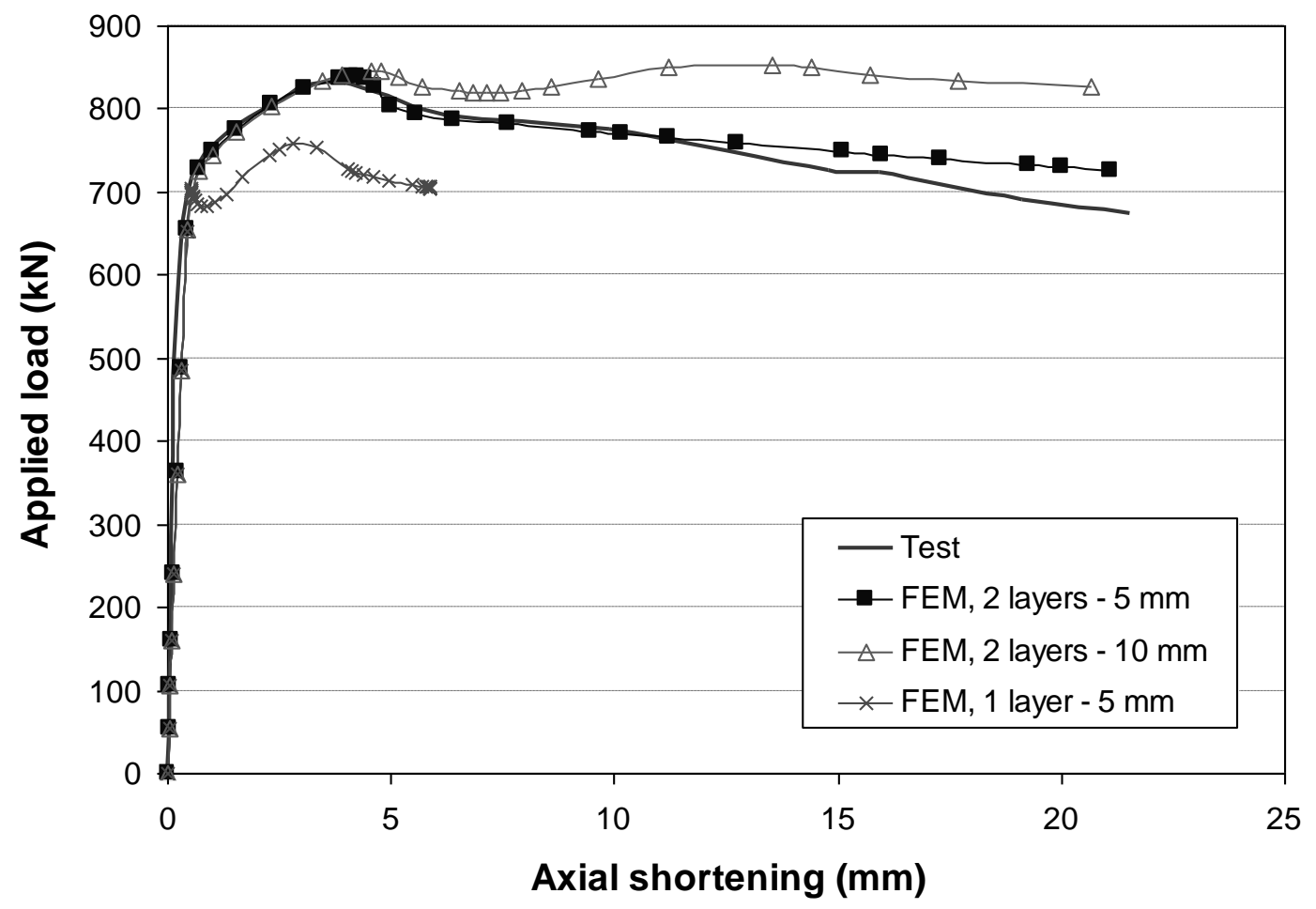

Fig. 2. Comparison of experimental and numerical results with different steel tube meshes, 150×75×4_C30. 


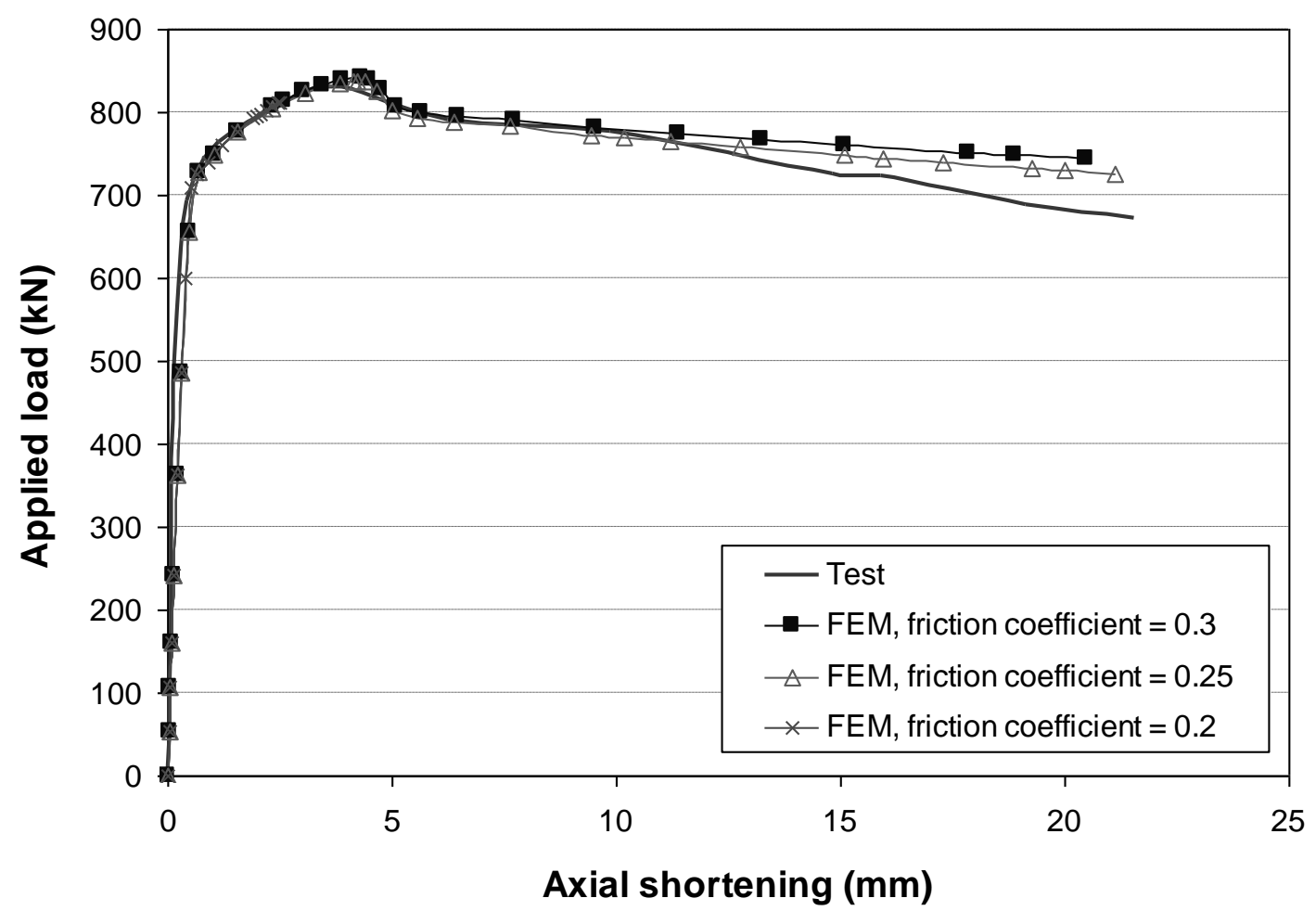

Fig. 3. Comparison of experimental and numerical results with different friction coefficients, 150×75×4_C30. 


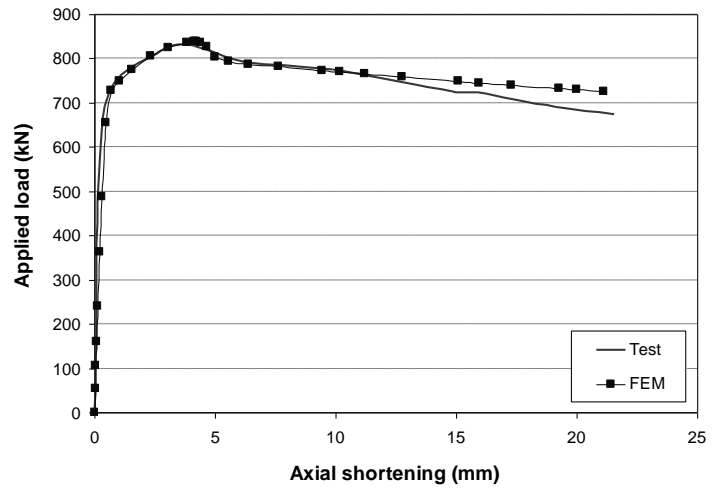

(a) $150 \times 75 \times 4 \_C 30$

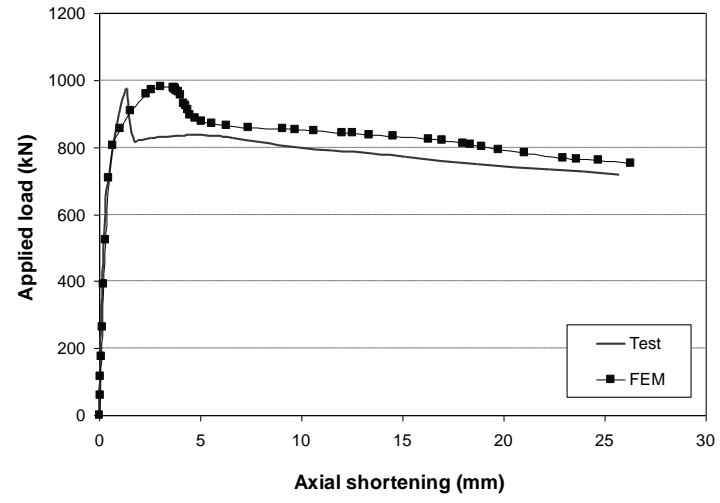

(b) $150 \times 75 \times 4+C 60$

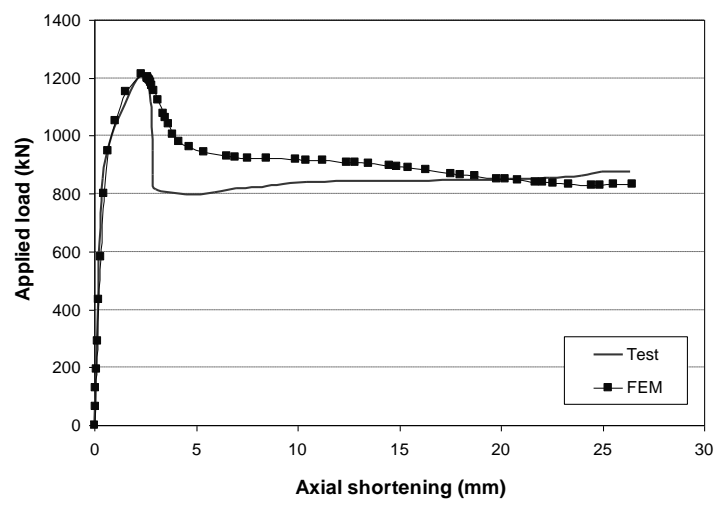

(c) $150 \times 75 \times 4+C 100$

Fig. 4. Comparison of experimental and numerical results, for $150 \times 75 \times 4 \mathrm{~mm}$ columns. 


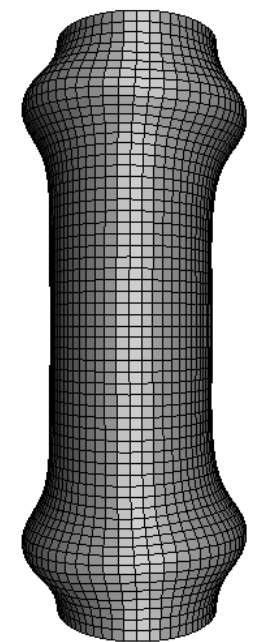

(a) $150 \times 75 \times 5 \_C 30$

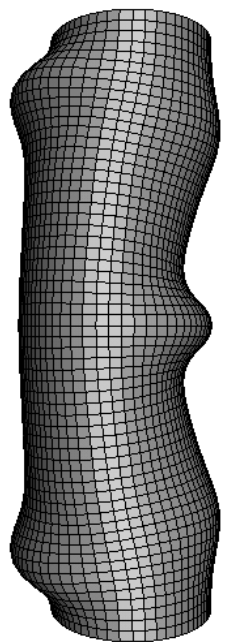

(b) $150 \times 75 \times 5 \_C 60$

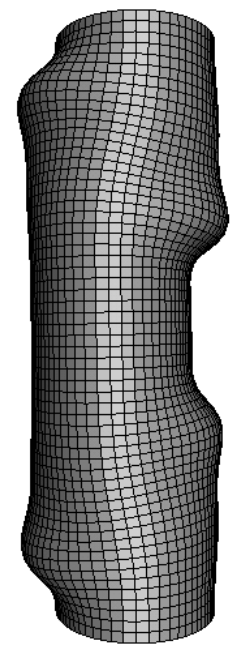

(c) $150 \times 75 \times 5+C 100$

Fig. 5. Different failure modes obtained from the FEA of the stub columns. 
Espinos A, Gardner L, Romero ML, Hospitaler A. Fire behaviour of concrete filled elliptical steel columns. Thin-Walled Struct. 2011;49:239-55. doi: 10.1016/j.tws.2010.10.008

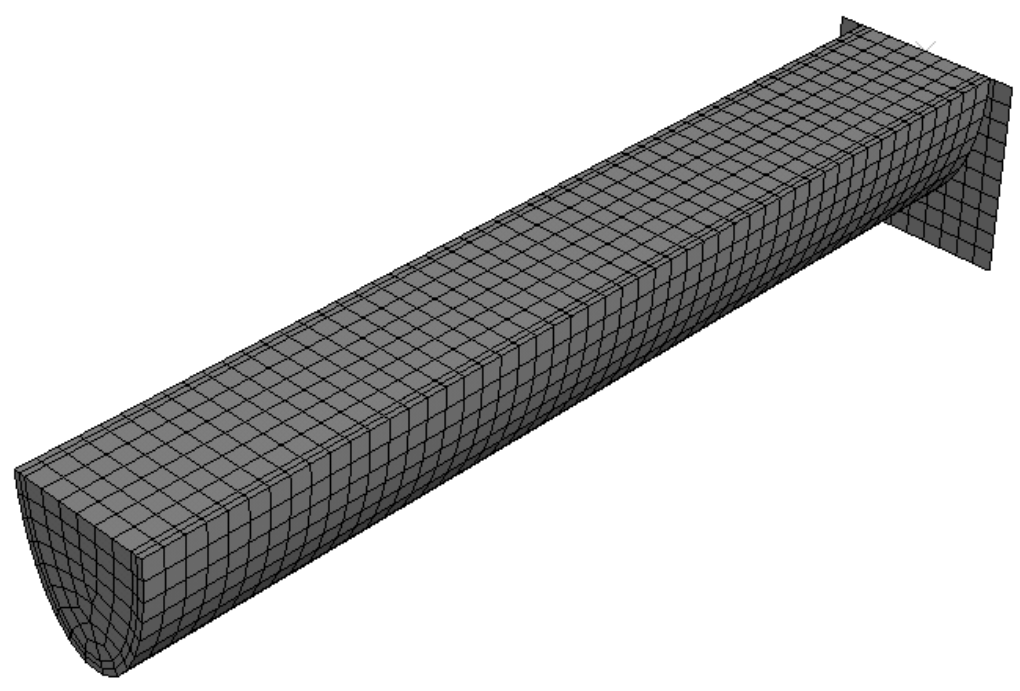

Fig. 6. Three-dimensional finite element model for slender CFEHS columns in fire. 
Espinos A, Gardner L, Romero ML, Hospitaler A. Fire behaviour of concrete filled elliptical steel columns. Thin-Walled Struct. 2011;49:239-55. doi: 10.1016/j.tws.2010.10.008

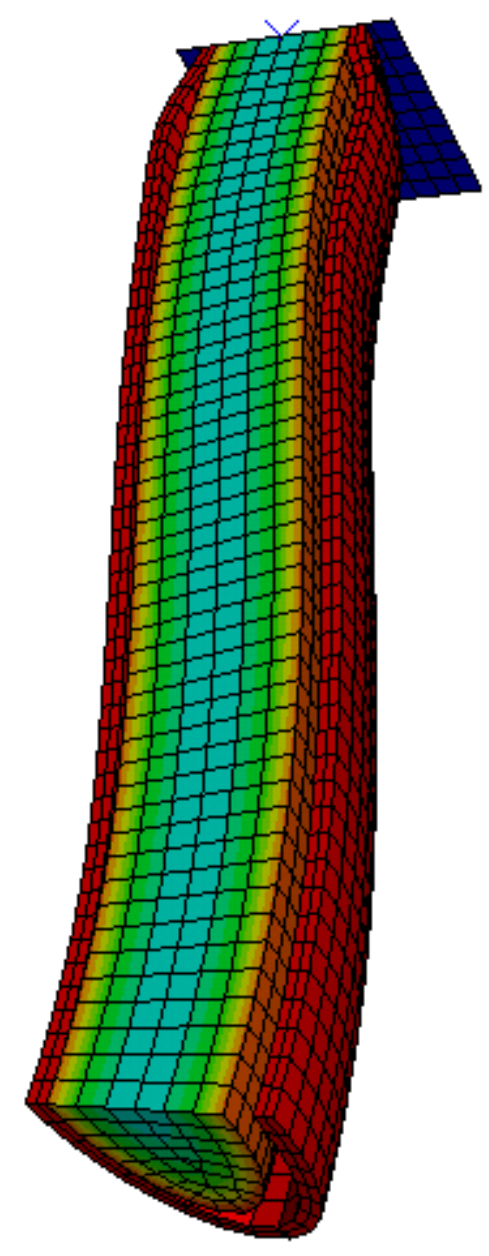

Fig. 7. Deformed shape after fire exposure, $300 \times 150 \times 12.5 \mathrm{~mm}, L=2 \mathrm{~m}, \mu=0.2$. 


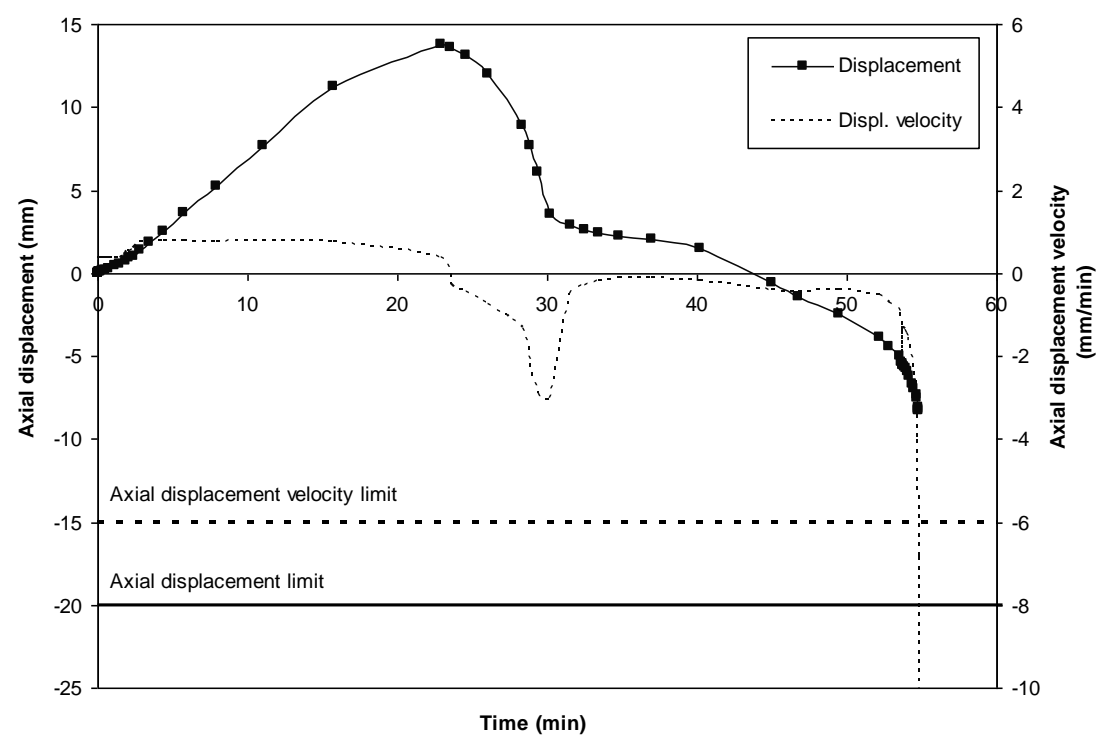

(a) $300 \times 150 \times 10 \mathrm{~mm}, L=2 \mathrm{~m}, \mu=0.2$

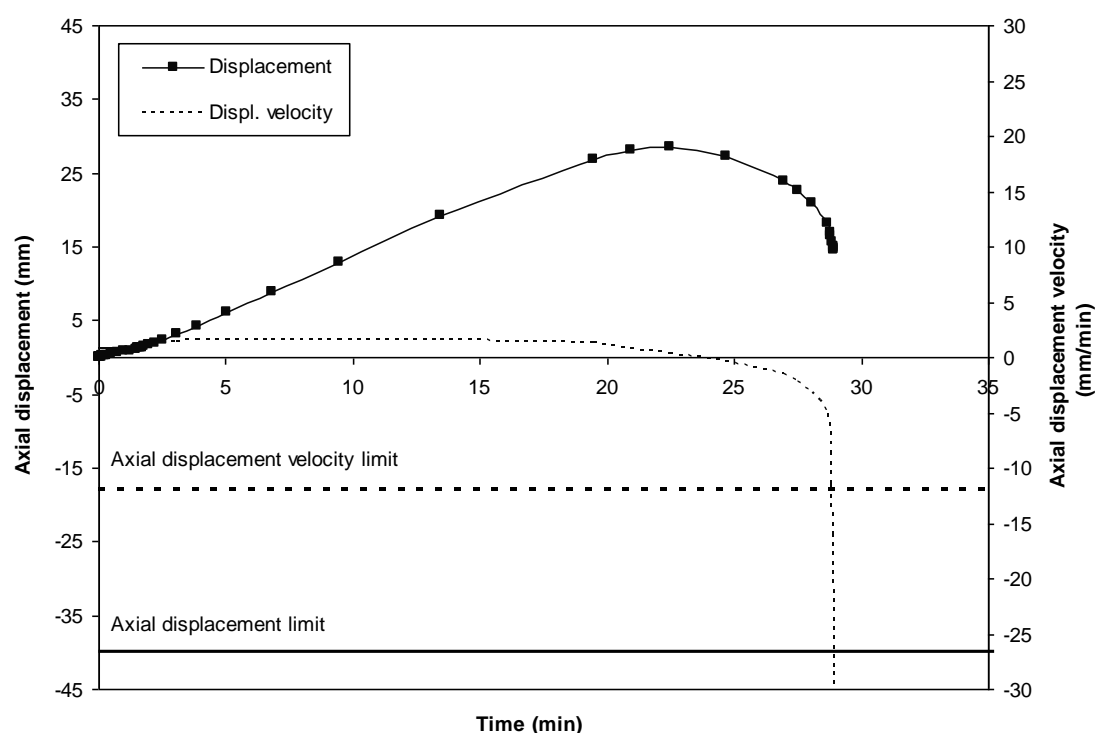

(b) $300 \times 150 \times 10 \mathrm{~mm}, L=4 \mathrm{~m}, \mu=0.2$

Fig. 8. Axial displacement versus time curves. 


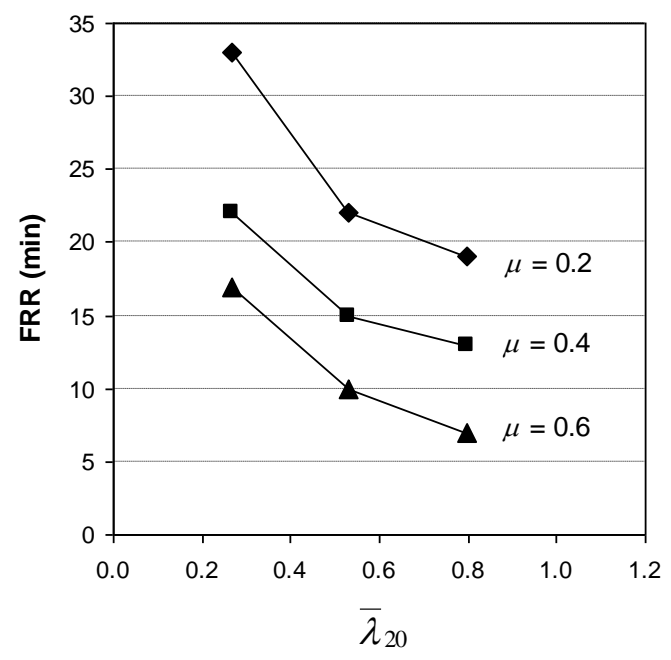

(a) $150 \times 75 \times 5 \mathrm{~mm}$

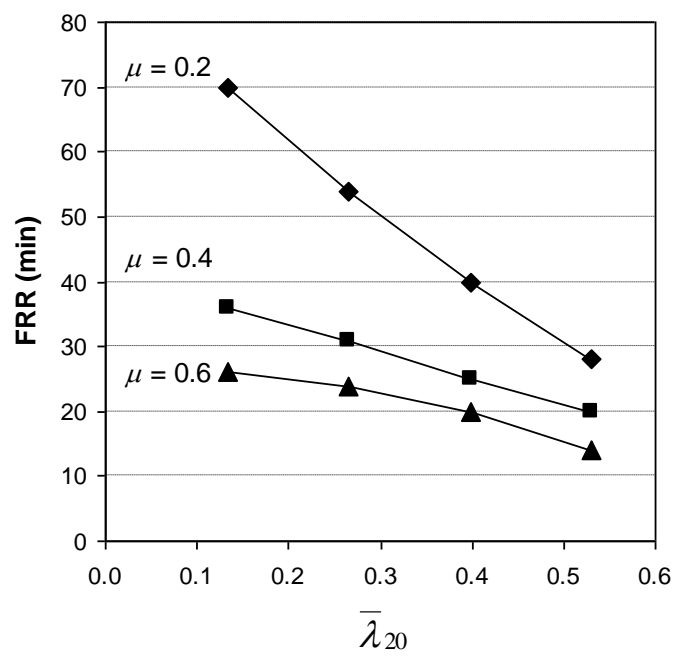

(b) $300 \times 150 \times 10 \mathrm{~mm}$

Fig. 9. Effect of the non-dimensional slenderness on the fire resistance rating of the columns. 


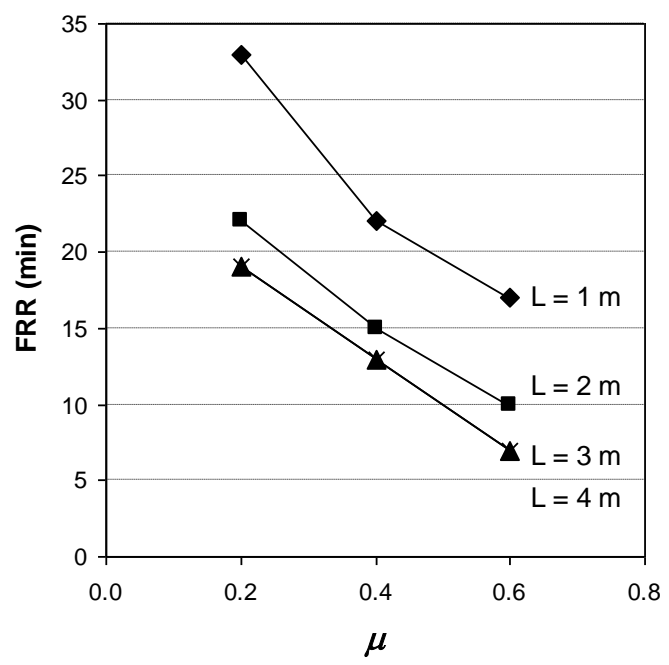

(a) $150 \times 75 \times 5 \mathrm{~mm}$

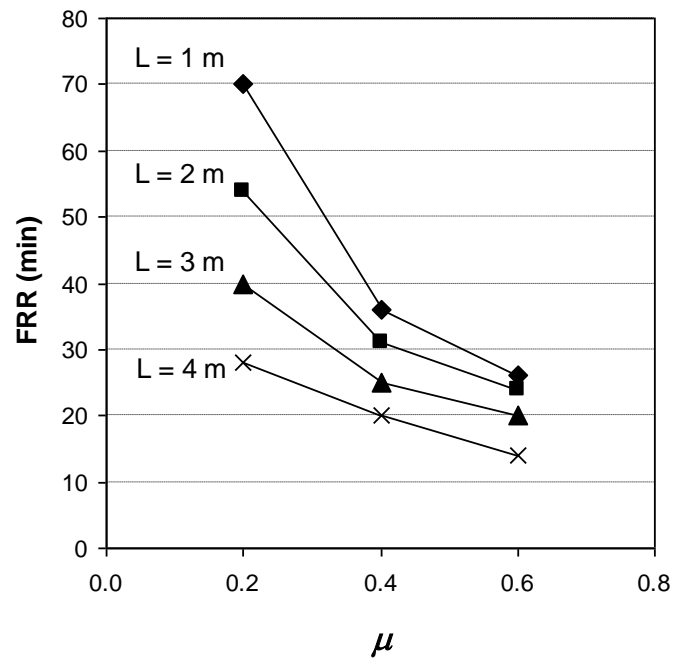

(b) $300 \times 150 \times 10 \mathrm{~mm}$

Fig. 10. Effect of the load level on the fire resistance rating of the columns. 


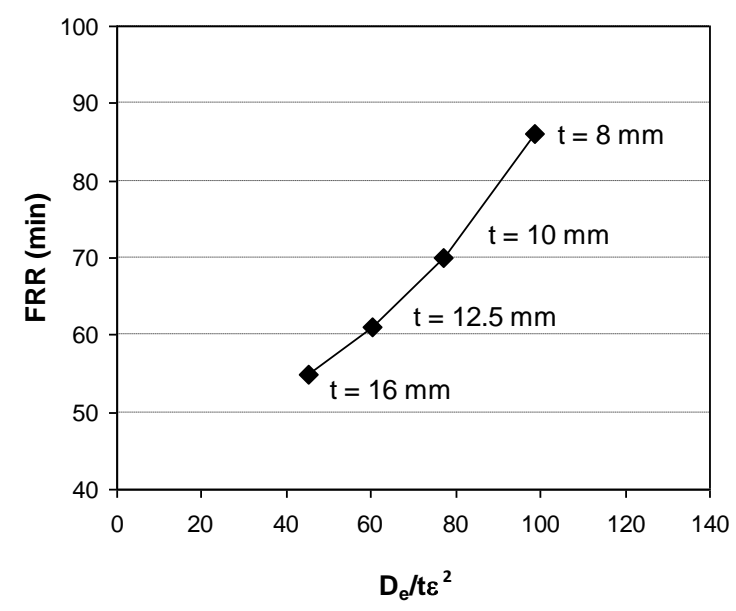

(a) $300 \times 150 \mathrm{~mm}, L=1 \mathrm{~m}, \mu=0.2$

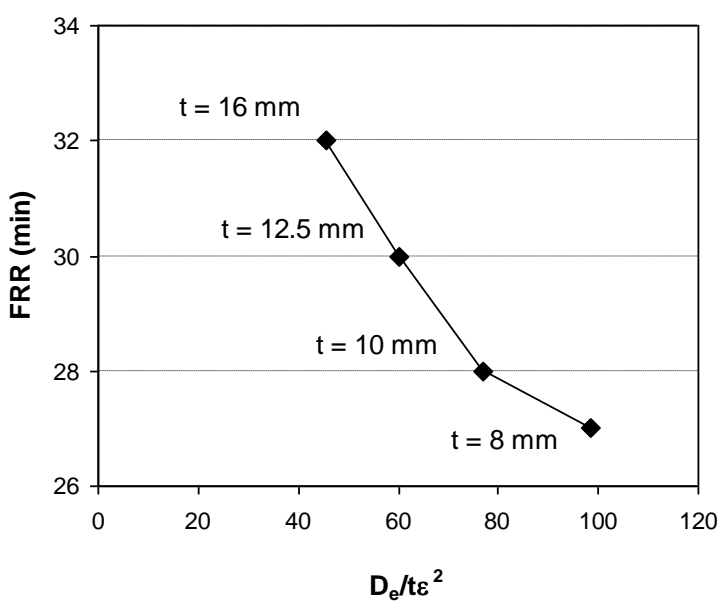

(b) $300 \times 150 \mathrm{~mm}, L=4 \mathrm{~m}, \mu=0.2$

Fig. 11. Effect of the cross-sectional slenderness on the fire resistance rating of the columns. 
Espinos A, Gardner L, Romero ML, Hospitaler A. Fire behaviour of concrete filled elliptical steel columns. Thin-Walled Struct.

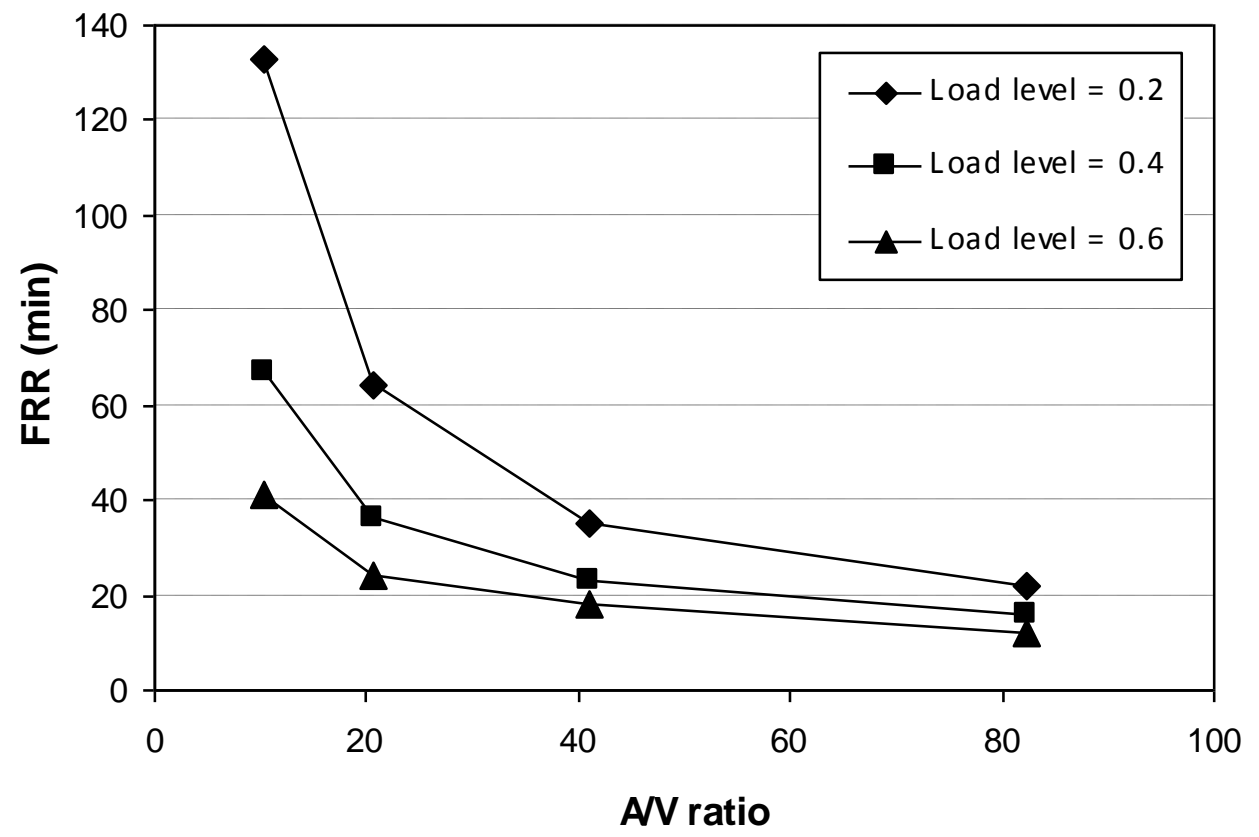

Fig. 12. Effect of the section factor on the fire resistance rating of the columns. 
Espinos A, Gardner L, Romero ML, Hospitaler A. Fire behaviour of concrete filled elliptical steel columns. Thin-Walled Struct. 2011;49:239-55. doi: 10.1016/j.tws.2010.10.008
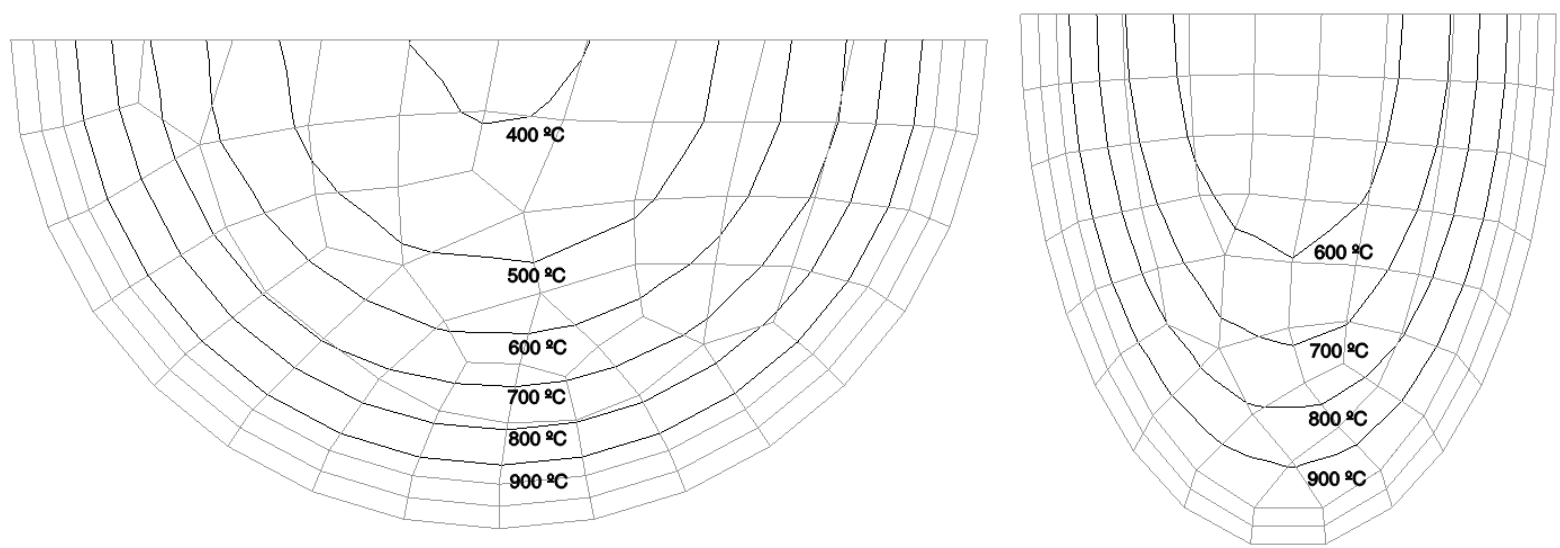

Fig. 13. Comparison of the cross-sectional temperature field between CFCHS $219.95 \times 10 \mathrm{~mm}$ and CFEHS $300 \times 150 \times 10 \mathrm{~mm}$, after 90 minutes of fire exposure. 


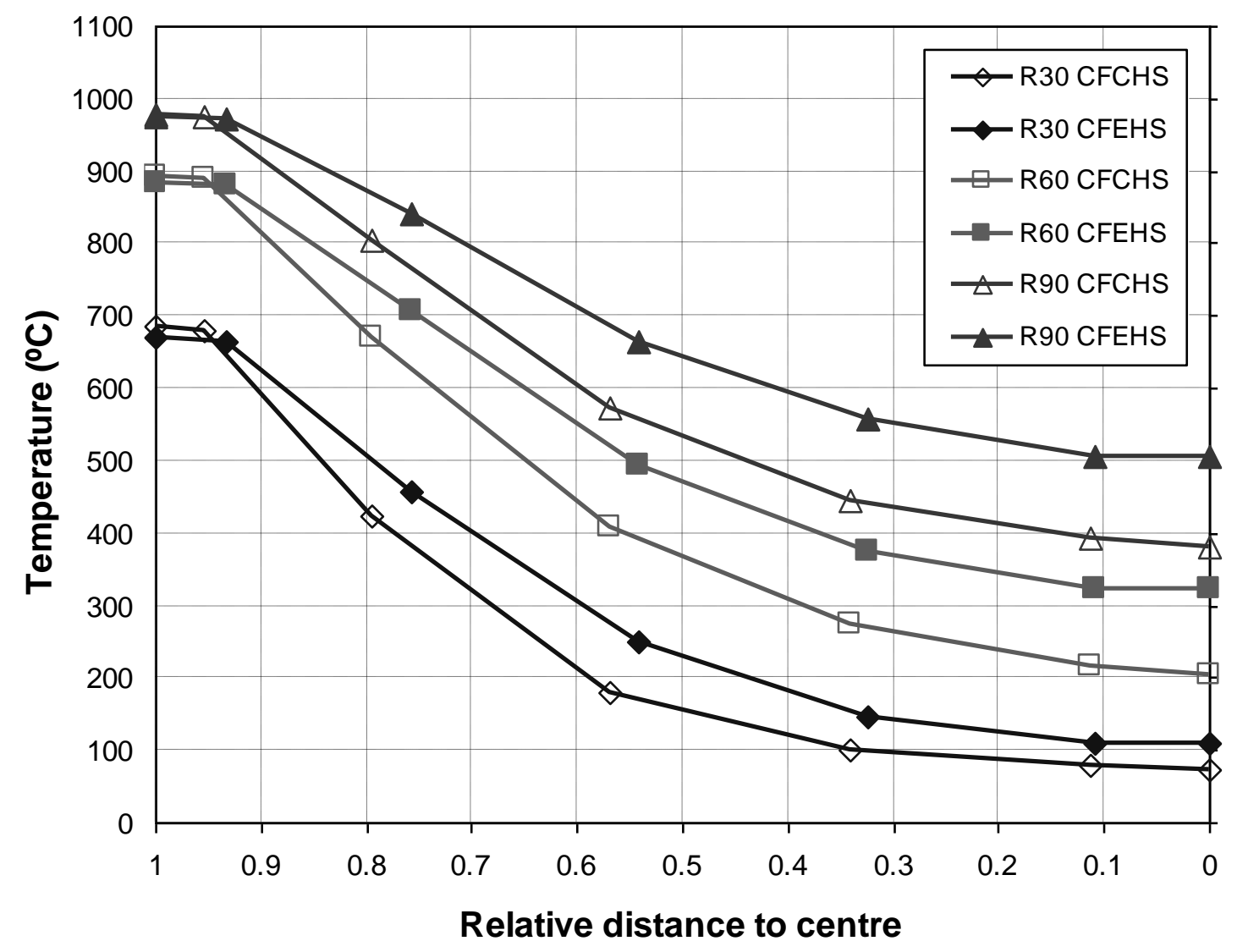

Fig. 14. Comparison of the cross-sectional temperature evolution between circular and elliptical columns for different exposure times. 


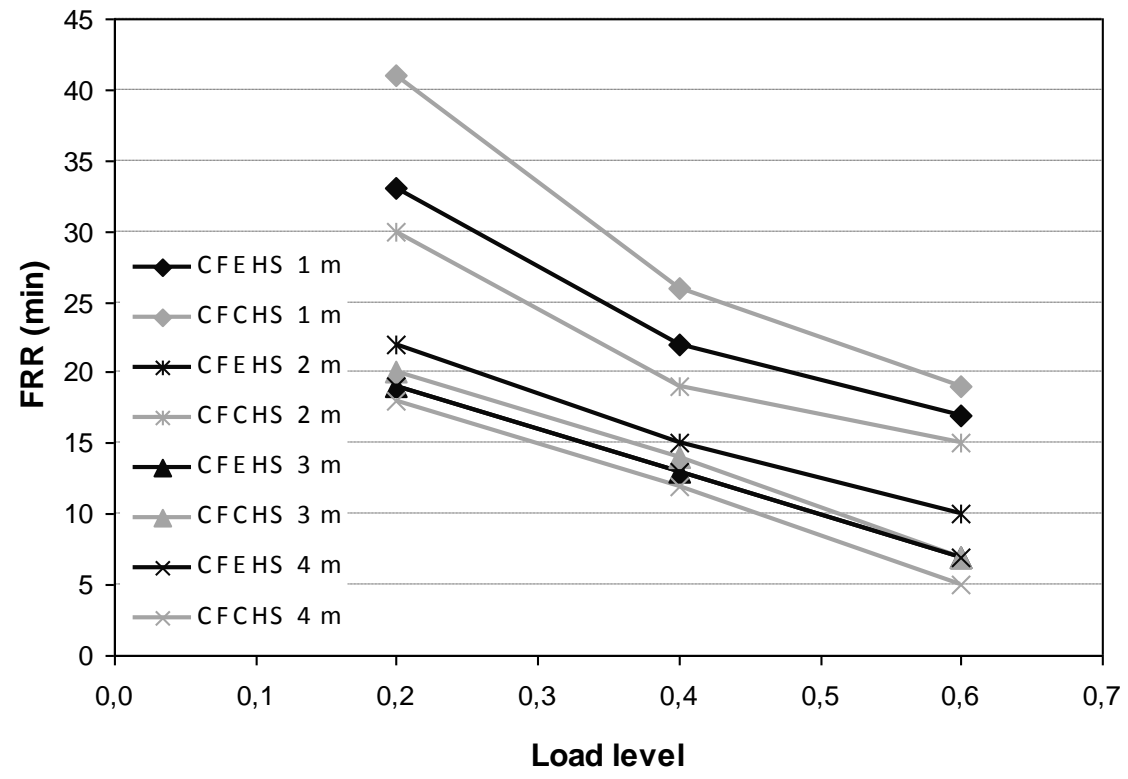

(a) $150 \times 75 \times 5 \mathrm{~mm}$

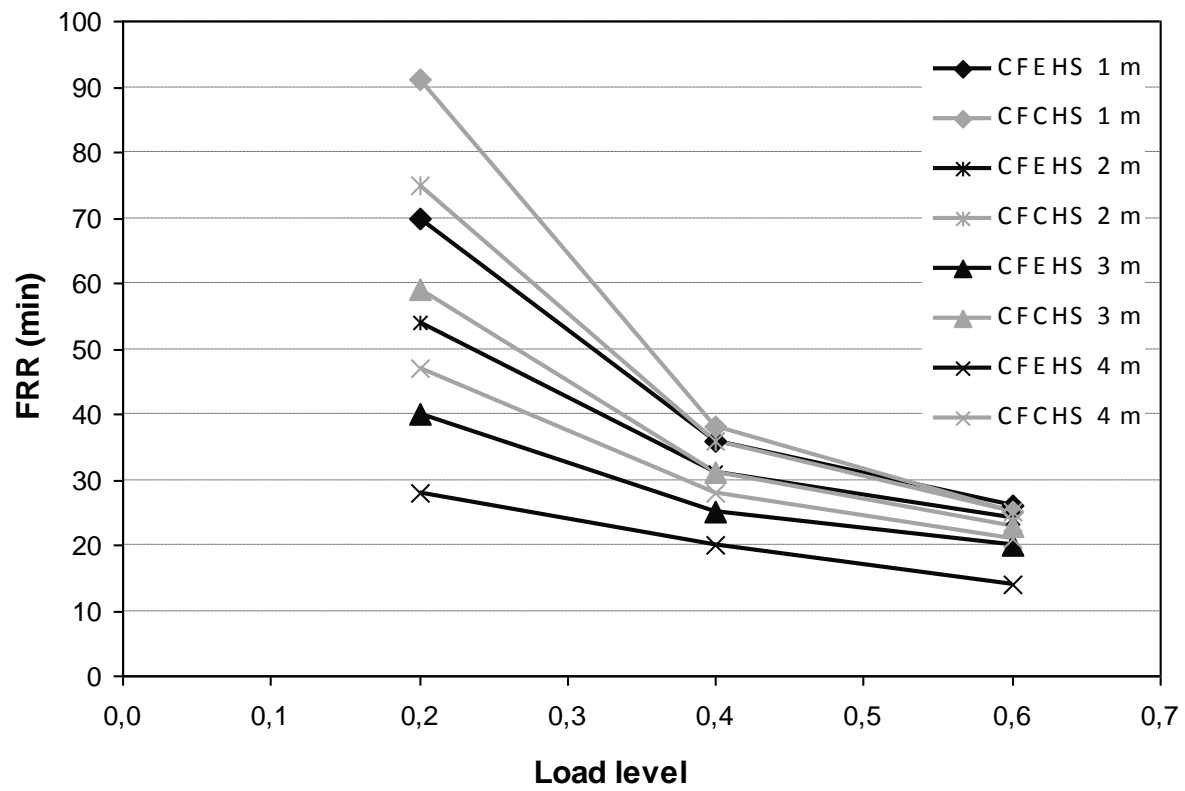

(b) $300 \times 150 \times 10 \mathrm{~mm}$

Fig. 15. Comparison between elliptical and circular columns for different lengths and load levels. 


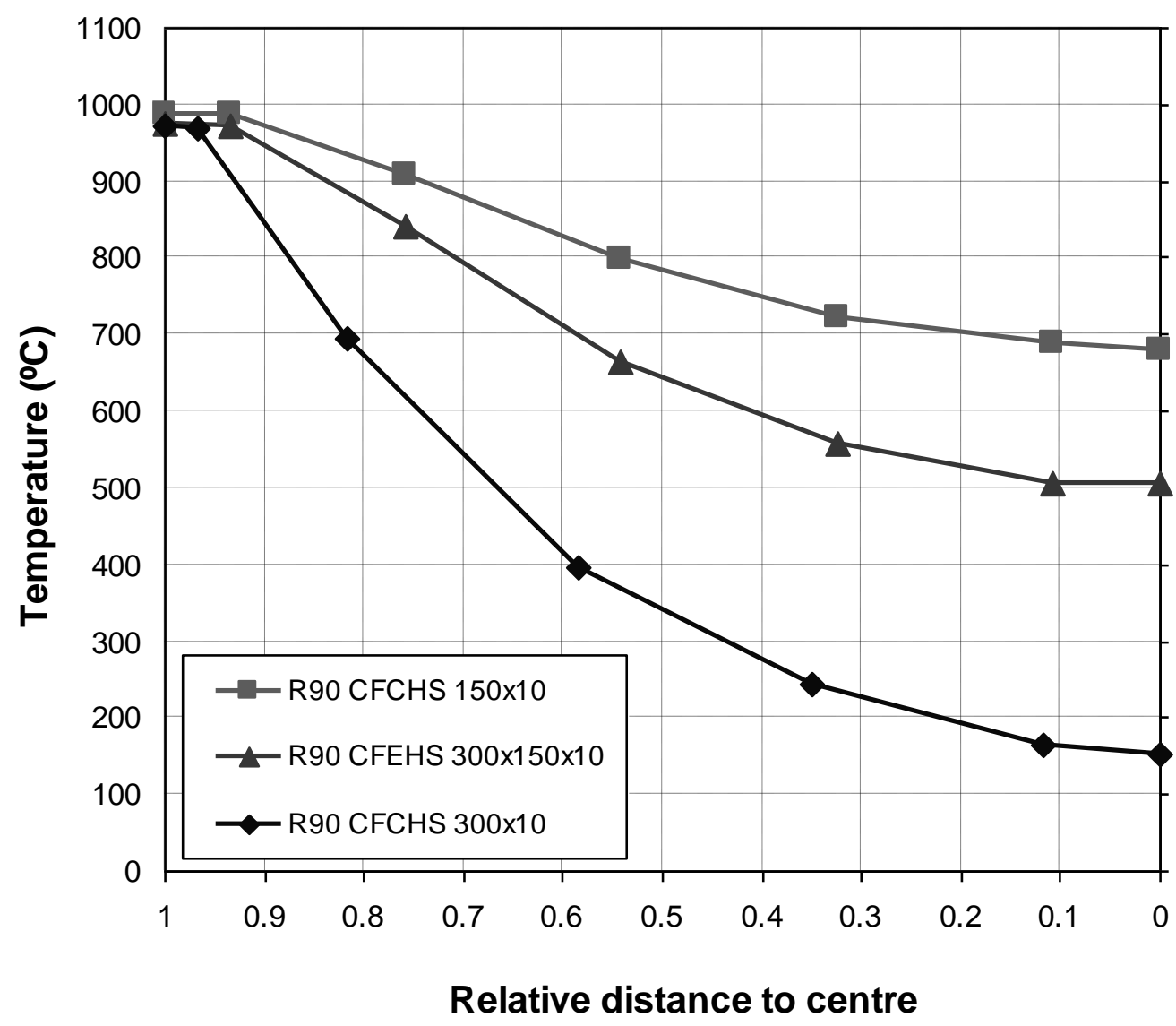

Fig. 16. Comparison of the cross-sectional temperature evolution between an elliptical and its bound circular columns after 90 minutes of fire exposure 


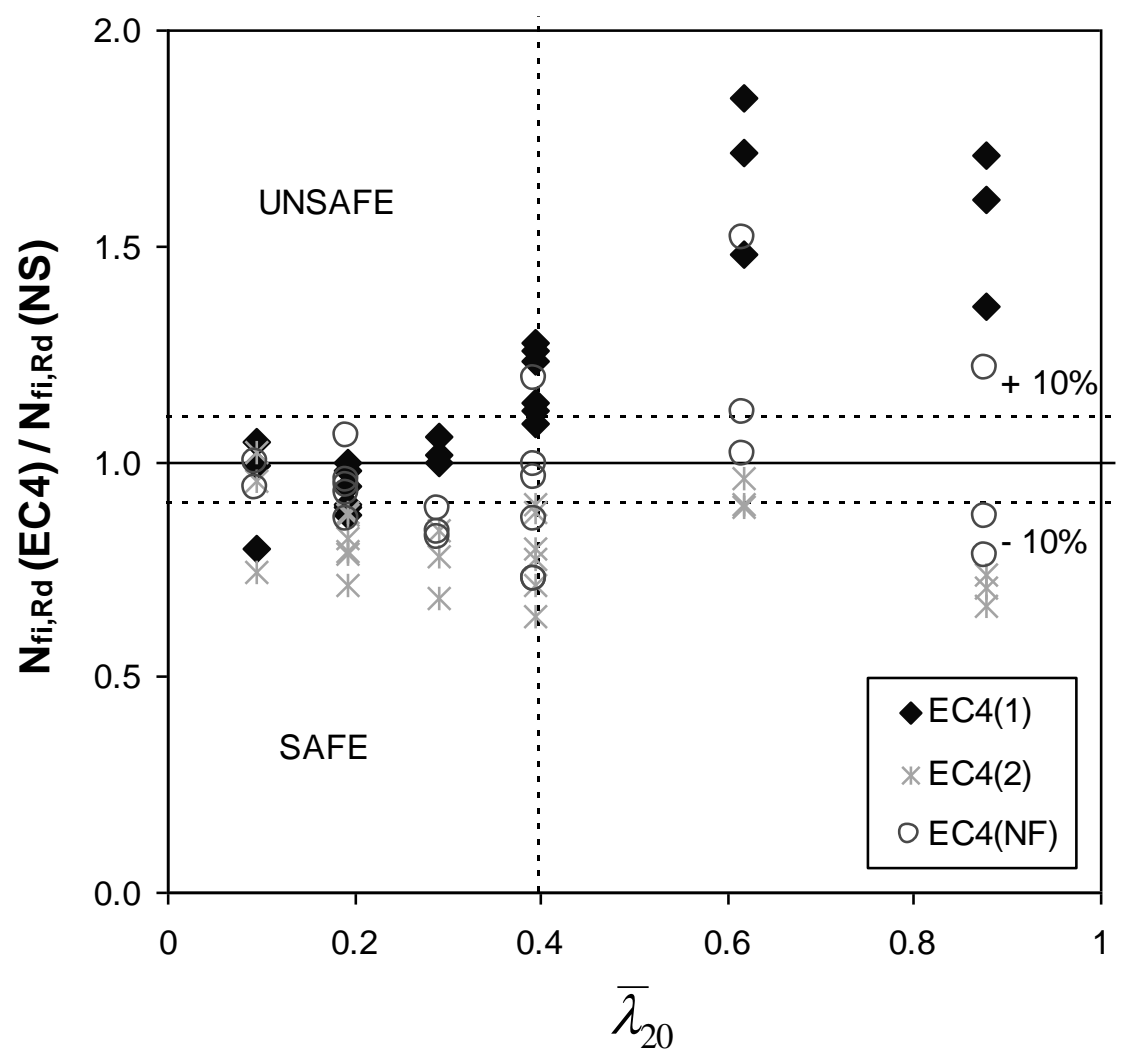

Fig. 17. Comparison between EN 1994-1-2 simple calculation model and numerical model, for CFCHS columns. 


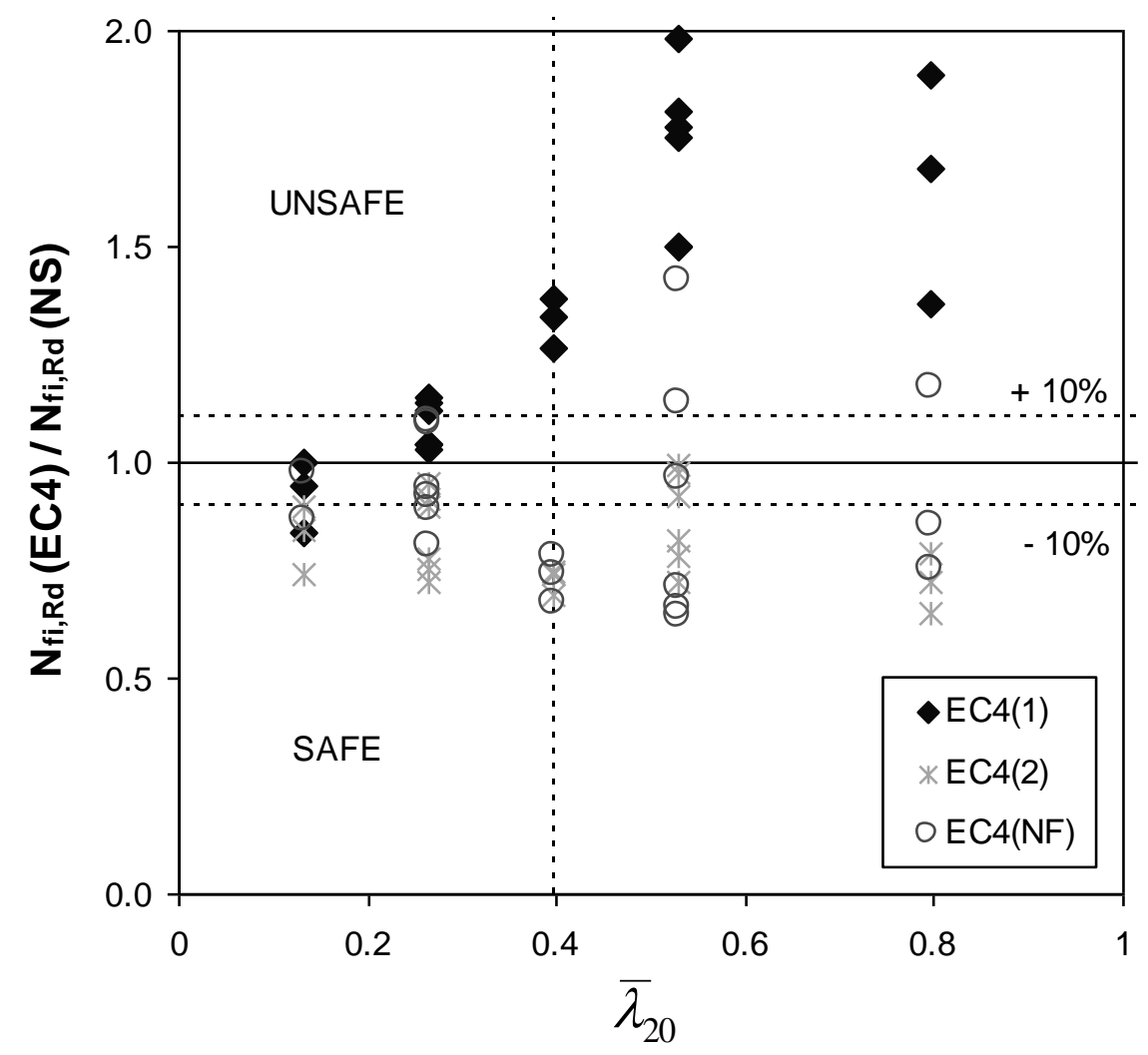

Fig. 18. Comparison between EN 1994-1-2 simple calculation model and numerical model, for CFEHS columns. 


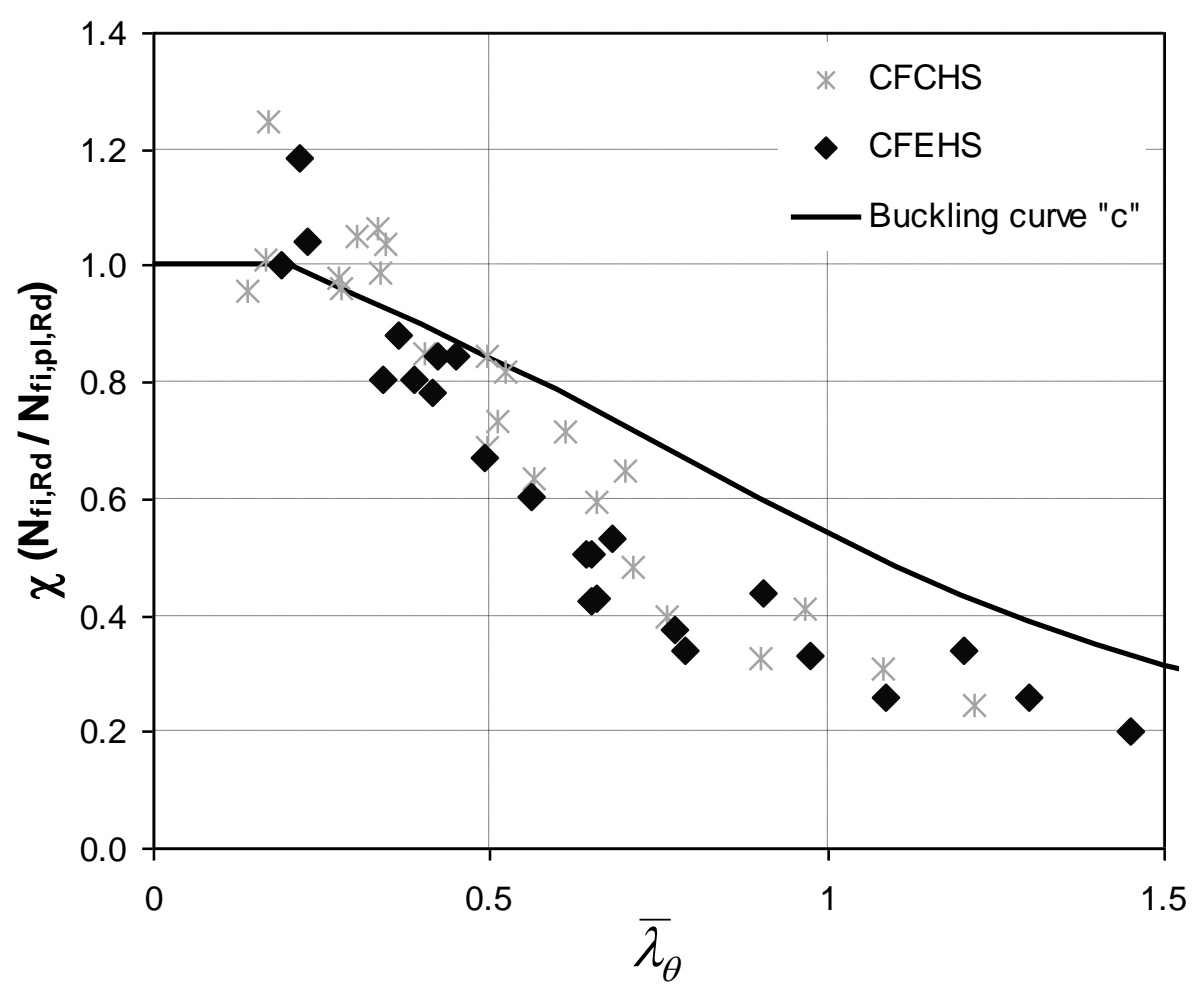

Fig. 19. Comparison of numerical results with EN 1993-1-1 buckling curve "c" (relative slenderness computed with coefficients equal to unity). 


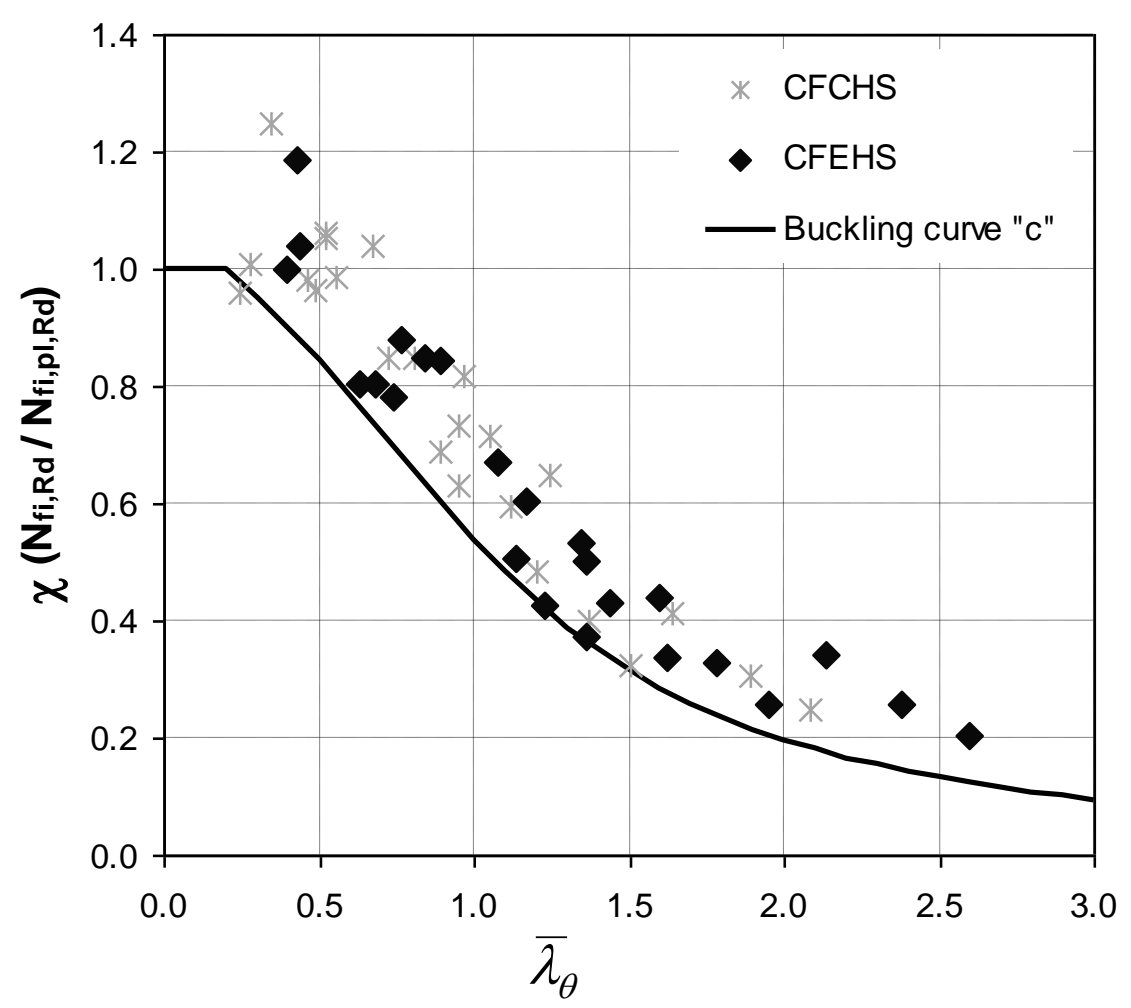

Fig. 20. Comparison of numerical results with EN 1993-1-1 buckling curve "c" (relative slenderness computed with French National Annex coefficients). 
Table 1. List of room temperature CFEHS stub columns analysed in this research

\begin{tabular}{|c|c|c|c|c|c|c|}
\hline $\begin{array}{c}\text { Specimen } \\
\text { designation }\end{array}$ & $\begin{array}{c}2 a \\
(\mathrm{~mm})\end{array}$ & $\begin{array}{c}2 b \\
(\mathrm{~mm})\end{array}$ & $\begin{array}{c}t \\
(\mathbf{m m})\end{array}$ & $\begin{array}{c}f_{y} \\
\left(\mathrm{~N} / \mathrm{mm}^{2}\right)\end{array}$ & $\begin{array}{c}f_{\text {ck,cube }} \\
\left(\mathrm{N} / \mathbf{m m}^{2}\right)\end{array}$ & $\begin{array}{c}N_{u, t e s t} \\
(\mathbf{k N})\end{array}$ \\
\hline $150 \times 75 \times 4$ C30 & 150 & 75 & 4 & 376.5 & 36.9 & 839 \\
\hline $150 \times 75 \times 4$ C60 & 150 & 75 & 4 & 376.5 & 59.8 & 974 \\
\hline $150 \times 75 \times 4 \_C 100$ & 150 & 75 & 4 & 376.5 & 98.4 & 1265 \\
\hline $150 \times 75 \times 5$ _C30 & 150 & 75 & 5 & 369 & 36.9 & 981 \\
\hline $150 \times 75 \times 5$ C60 & 150 & 75 & 5 & 369 & 59.8 & 1084 \\
\hline $150 \times 75 \times 5 \_C 100$ & 150 & 75 & 5 & 369 & 98.4 & 1296 \\
\hline $150 \times 75 \times 6.3 \_C 30$ & 150 & 75 & 6.3 & 400.5 & 36.9 & 1193 \\
\hline $150 \times 75 \times 6.3 \_C 60$ & 150 & 75 & 6.3 & 400.5 & 59.8 & 1280 \\
\hline $150 \times 75 \times 6.3 \_C 100$ & 150 & 75 & 6.3 & 400.5 & 98.4 & 1483 \\
\hline
\end{tabular}


Table 2. $\quad$ Measured and predicted maximum axial loads

\begin{tabular}{|c|c|c|c|}
\hline \multirow{2}{*}{$\begin{array}{c}\text { Specimen } \\
\text { designation }\end{array}$} & \multicolumn{2}{|c|}{ Maximum load $(\mathrm{kN})$} & \multirow{2}{*}{$\xi=\frac{N_{u, t e s t}}{N_{u, F E M}}$} \\
\hline & Test, $N_{u, t e s t}$ & Simulation, $N_{u, F E M}$ & \\
\hline $150 \times 75 \times 4$ C30 & 839 & 838 & 1.00 \\
\hline $150 \times 75 \times 4$ C60 & 974 & 982 & 0.99 \\
\hline $150 \times 75 \times 4$ _C100 & 1265 & 1213 & 1.04 \\
\hline $150 \times 75 \times 5 \_C 30$ & 981 & 963 & 1.02 \\
\hline $150 \times 75 \times 5$ C60 & 1084 & 1095 & 0.99 \\
\hline 150×75×5_C100 & 1296 & 1316 & 0.98 \\
\hline $150 \times 75 \times 6.3$ C 30 & 1192 & 1178 & 1.01 \\
\hline $150 \times 75 \times 6.3 \_C 60$ & 1280 & 1304 & 0.98 \\
\hline \multirow[t]{3}{*}{$150 \times 75 \times 6.3 \_C 100$} & 1483 & 1506 & 0.98 \\
\hline & \multicolumn{2}{|l|}{ Average } & 1.00 \\
\hline & \multicolumn{2}{|c|}{ Standard deviation } & $\mathbf{0 . 0 2}$ \\
\hline
\end{tabular}


Table 3. List of CFEHS columns exposed to fire analysed in this research

\begin{tabular}{|c|c|c|c|c|c|c|c|c|c|c|c|c|c|}
\hline $\begin{array}{c}\text { Specimen } \\
\text { designation }\end{array}$ & $\begin{array}{c}2 a \\
(\mathrm{~mm})\end{array}$ & $\begin{array}{c}2 b \\
(\mathrm{~mm})\end{array}$ & $\begin{array}{c}t \\
(\mathrm{~mm})\end{array}$ & $\begin{array}{c}L \\
(\mathbf{m m})\end{array}$ & $\mu$ & $\begin{array}{c}N \\
(\mathbf{k N})\end{array}$ & $\begin{array}{l}\text { FRR } \\
(\mathrm{min})\end{array}$ & $\mu$ & $\begin{array}{c}N \\
(\mathbf{k N})\end{array}$ & $\begin{array}{l}\text { FRR } \\
(\mathrm{min})\end{array}$ & $\mu$ & $\begin{array}{c}N \\
(\mathbf{k N})\end{array}$ & $\begin{array}{l}\text { FRR } \\
(\mathrm{min})\end{array}$ \\
\hline $5 \times 37.5 \times 2 \_0.5$ & 75 & 37.5 & 2 & 500 & 0.20 & 30 & 22 & 0.40 & 60 & 16 & 0.60 & 91 & 12 \\
\hline 2 & & 15 & & 1000 & 20 & 121 & 35 & 40 & 241 & 29 & 0.60 & 362 & 19 \\
\hline . & & 75 & 4 & U & 20 & 112 & 23 & 40 & 224 & 16 & .60 & 337 & 11 \\
\hline 시 & & 75 & 4 & 0 & 20 & 98 & 20 & 40 & 197 & 13 & 60 & 295 & 5 \\
\hline 21 & & 75 & 4 & 0 & .20 & 77 & 19 & 40 & 155 & 13 & 60 & 232 & 7 \\
\hline 1 & & 75 & 5 & 000 & 0.20 & 146 & 33 & 0.40 & 293 & 23 & 0.60 & 439 & 18 \\
\hline$\times 75 x$ & 50 & 75 & 5 & 000 & 0.20 & 136 & 22 & .40 & 272 & 16 & 0.60 & 407 & 11 \\
\hline $150 \times 75 \times$ & 0 & 13 & 5 & 3000 & 0.20 & 119 & 20 & 0.40 & 237 & 14 & 0.60 & 356 & 5 \\
\hline $150 \times 75 \times 5 \_4$ & U & 13 & $J$ & 4000 & 0.20 & 93 & 20 & 0.40 & 185 & 14 & 0.60 & 278 & 7 \\
\hline $150 \times 75 \times 6.3 \_1$ & 50 & 75 & 6.3 & 1000 & 0.20 & 174 & 32 & 0.40 & 347 & 22 & 0.60 & 521 & 20 \\
\hline $150 \times 75 \times 6.3 \_2$ & 50 & 75 & 6.3 & 2000 & 0.20 & 161 & 23 & 0.40 & 322 & 16 & 0.60 & 483 & 10 \\
\hline $150 \times 75 \times 6$ & U & 75 & 6.3 & 3000 & 0.20 & 141 & 20 & 0.40 & 281 & 14 & 0.60 & 422 & 2 \\
\hline $150 \times 75 \times$ & 50 & 75 & 6.3 & 4000 & 0.20 & 110 & 19 & 0.40 & 219 & 14 & 0.60 & 329 & 1 \\
\hline $300 \times 1$ & 00 & 50 & 8 & 1000 & 0.20 & 490 & 87 & 0.40 & 979 & 41 & 0.60 & 1469 & 26 \\
\hline $300 \times 150$ & 00 & 150 & 8 & 2000 & 0.20 & 483 & 65 & 0.40 & 966 & 37 & 0.60 & 1449 & 25 \\
\hline $300 \times 150$ & 00 & 150 & 8 & 3000 & 0.20 & 467 & 48 & 0.40 & 935 & 29 & 0.60 & 1402 & 21 \\
\hline $300 \times 150 \times 8 \_4$ & 00 & 150 & 8 & 4000 & 0.20 & 449 & 28 & 0.40 & 898 & 19 & 0.60 & 1347 & 14 \\
\hline $300 \times 150 \times$ & 300 & 150 & 10 & 1000 & 0.20 & 594 & 71 & 0.40 & 1188 & 36 & 0.60 & 1782 & 25 \\
\hline $300 \times 150 \times 10 \_2$ & 300 & 50 & 1 & 2000 & 0.20 & 585 & 55 & 0.40 & 1171 & 32 & 0.60 & 1756 & 24 \\
\hline $300 \times 150 \times 10 \_3$ & 300 & 150 & 10 & 3000 & 0.20 & 566 & 41 & 0.40 & 1132 & 25 & 0.60 & 1699 & 20 \\
\hline $300 \times 150 \times 10 \_4$ & 300 & 150 & 10 & 4000 & 0.20 & 543 & 29 & 0.40 & 1086 & 20 & 0.60 & 1630 & 15 \\
\hline $300 \times 1$ & 3 & & & 1000 & 0.20 & 700 & 61 & 0.40 & 1401 & 34 & 0.60 & 2101 & 26 \\
\hline $300 \times 150$ & 300 & & & 2000 & 0.20 & 690 & 49 & 0.40 & 1381 & 31 & 0.60 & 2071 & 24 \\
\hline $300 \times 150 \times 12.5 \_3$ & & & & 3000 & 0.20 & 668 & 37 & 0.40 & 1335 & 26 & 0.60 & 2003 & 21 \\
\hline $300 \times 150 \times 12.5 \_4$ & 300 & & 12.5 & 4000 & 0.20 & 640 & 31 & 0.40 & 1281 & 22 & 0.60 & 1921 & 15 \\
\hline $300 \times 150 \times 16 \_1$ & 300 & 150 & & 1000 & 0.20 & 845 & 55 & 0.40 & 1690 & 35 & 0.60 & 2536 & 27 \\
\hline $300 \times 150 \times 16 \_2$ & 300 & 150 & 16 & 2000 & 0.20 & 832 & 48 & 0.40 & 1665 & 32 & 0.60 & 2497 & 25 \\
\hline $300 \times 150 \times 16 \_3$ & 300 & 150 & 16 & 3000 & 0.20 & 805 & 36 & 0.40 & 1610 & 27 & 0.60 & 2415 & 22 \\
\hline 300×150×16_4 & 300 & 150 & 16 & 4000 & 0.20 & 772 & 33 & 0.40 & 1543 & 24 & 0.60 & 2315 & 16 \\
\hline $600 \times 300 \times 16 \_4$ & 600 & 300 & 16 & 4000 & 0.20 & 1932 & 133 & 0.40 & 3864 & 67 & 0.60 & 5796 & 41 \\
\hline
\end{tabular}


Table 4. List of CFCHS columns exposed to fire analysed in this research

\begin{tabular}{|l|l|c|c|c|c|c|c|c|c|c|c|c|c|}
\hline $\begin{array}{c}\text { Specimen } \\
\text { designation }\end{array}$ & $\begin{array}{c}\text { Equivalent } \\
\text { CFEHS column }\end{array}$ & $\begin{array}{c}\boldsymbol{D} \\
(\mathbf{m m})\end{array}$ & $\begin{array}{c}\boldsymbol{t} \\
(\mathbf{m m})\end{array}$ & $\begin{array}{c}\boldsymbol{L} \\
(\mathbf{m m})\end{array}$ & $\boldsymbol{\mu}$ & $\begin{array}{c}\boldsymbol{N} \\
(\mathbf{k N})\end{array}$ & $\begin{array}{c}\text { FRR } \\
(\mathbf{m i n})\end{array}$ & $\boldsymbol{\mu}$ & $\begin{array}{c}\boldsymbol{N} \\
(\mathbf{k N})\end{array}$ & $\begin{array}{c}\text { FRR } \\
(\mathbf{m i n})\end{array}$ & $\begin{array}{c}\boldsymbol{N} \\
(\mathbf{k N})\end{array}$ & $\begin{array}{c}\text { FRR } \\
(\mathbf{m i n})\end{array}$ \\
\hline $108.74 \times 5 \_1$ & $150 \times 75 \times 5 \_1$ & 108.74 & 5 & 1000 & 0.20 & 146 & 41 & 0.40 & 293 & 26 & 0.60 & 439 & 19 \\
\hline $106.38 \times 5 \_2$ & $150 \times 75 \times 5 \_2$ & 106.38 & 5 & 2000 & 0.20 & 136 & 30 & 0.40 & 272 & 19 & 0.60 & 407 & 15 \\
\hline $101.64 \times 5 \_3$ & $150 \times 75 \times 5 \_3$ & 101.64 & 5 & 3000 & 0.20 & 119 & 20 & 0.40 & 237 & 14 & 0.60 & 356 & 7 \\
\hline $95.29 \times 5 \_4$ & $150 \times 75 \times 5 \_4$ & 95.29 & 5 & 4000 & 0.20 & 93 & 18 & 0.40 & 185 & 12 & 0.60 & 278 & 5 \\
\hline $219.95 \times 10 \_1$ & $300 \times 150 \times 10 \_1$ & 219.95 & 10 & 1000 & 0.20 & 594 & 91 & 0.40 & 1188 & 38 & 0.60 & 1782 & 25 \\
\hline $217.48 \times 10 \_2$ & $300 \times 150 \times 10 \_2$ & 217.48 & 10 & 2000 & 0.20 & 585 & 75 & 0.40 & 1171 & 36 & 0.60 & 1756 & 25 \\
\hline $215.39 \times 10 \_3$ & $300 \times 150 \times 10 \_3$ & 215.39 & 10 & 3000 & 0.20 & 566 & 59 & 0.40 & 1132 & 31 & 0.60 & 1699 & 23 \\
\hline $212.77 \times 10 \_4$ & $300 \times 150 \times 10 \_4$ & 212.77 & 10 & 4000 & 0.20 & 543 & 47 & 0.40 & 1086 & 28 & 0.60 & 1630 & 21 \\
\hline
\end{tabular}


Espinos A, Gardner L, Romero ML, Hospitaler A. Fire behaviour of concrete filled elliptical steel columns. Thin-Walled Struct. 2011;49:239-55. doi: 10.1016/j.tws.2010.10.008

Table 5. Values of coefficient $\varphi_{a, \theta}$ according to the French National Annex to EN 1994-1-2 [39]

\begin{tabular}{|lccccc|}
\hline & \multicolumn{5}{c|}{$\boldsymbol{B}$ or $\boldsymbol{D}(\mathbf{m m})$} \\
\cline { 2 - 6 } & 100 & 150 & 200 & 250 & $\begin{array}{c}350 \text { to } \\
610\end{array}$ \\
\hline R30 & 0.30 & 0.23 & 0.15 & 0.15 & 0.15 \\
R60 & - & 0.30 & 0.23 & 0.15 & 0.15 \\
R90 & - & - & 0.30 & 0.20 & 0.15 \\
R120 & - & - & 0.30 & 0.20 & 0.20 \\
\hline
\end{tabular}


Table 6. Comparison of numerical simulation (NS) results with existing design guidance, for CFCHS columns

\begin{tabular}{|c|c|c|c|c|c|}
\hline & & & Buckling res & tance at crit & al temperature \\
\hline $\begin{array}{c}\text { Specimen } \\
\text { designation }\end{array}$ & $\begin{array}{c}N \\
(\mathbf{k N})\end{array}$ & $\begin{array}{l}\text { FRR } \\
(\mathrm{min})\end{array}$ & EC4(1)/NS & EC4(2)/NS & EC4(NF)/NS \\
\hline $108.74 \times 5 \_1(0.2)$ & 146 & 41 & 0.90 & 0.79 & 1.06 \\
\hline $108.74 \times 5 \_1(0.4)$ & 293 & 26 & 0.88 & 0.78 & 0.96 \\
\hline $108.74 \times 5 \_1(0.6)$ & 439 & 19 & 0.98 & 0.88 & 0.93 \\
\hline $106.38 \times 5 \_2(0.2)$ & 136 & 30 & 1.26 & 0.80 & 0.99 \\
\hline $106.38 \times 5 \_2(0.4)$ & 272 & 19 & 1.27 & 0.90 & 1.19 \\
\hline $106.38 \times 5 \_2(0.6)$ & 407 & 15 & 1.23 & 0.88 & 0.96 \\
\hline $101.64 \times 5 \_3(0.2)$ & 119 & 20 & 1.84 & 0.96 & 1.52 \\
\hline $101.64 \times 5 \_3(0.4)$ & 237 & 14 & 1.72 & 0.90 & 1.11 \\
\hline $101.64 \times 5 \_3(0.6)$ & 356 & 7 & 1.48 & 0.89 & 1.01 \\
\hline $95.29 \times 5 \_4(0.2)$ & 93 & 18 & 1.71 & 0.74 & 1.21 \\
\hline $95.29 \times 5 \_4(0.4)$ & 185 & 12 & 1.61 & 0.70 & 0.87 \\
\hline $95.29 \times 5 \_4(0.6)$ & 278 & 5 & 1.36 & 0.67 & 0.78 \\
\hline 219.95×10_1(0.2) & 594 & 91 & 0.80 & 0.74 & - \\
\hline 219.95×10_1(0.4) & 1188 & 38 & 0.99 & 0.95 & 1.00 \\
\hline 219.95×10_1(0.6) & 1782 & 25 & 1.04 & 1.02 & 0.94 \\
\hline $217.48 \times 10 \_2(0.2)$ & 585 & 75 & 0.89 & 0.71 & - \\
\hline $217.48 \times 10 \_2(0.4)$ & 1171 & 36 & 0.94 & 0.82 & 0.94 \\
\hline $217.48 \times 10 \_2(0.6)$ & 1756 & 25 & 1.00 & 0.88 & 0.87 \\
\hline $215.39 \times 10 \_3(0.2)$ & 566 & 59 & 1.01 & 0.68 & 0.82 \\
\hline $215.39 \times 10 \_3(0.4)$ & 1132 & 31 & 1.00 & 0.78 & 0.89 \\
\hline $215.39 \times 10 \_3(0.6)$ & 1699 & 23 & 1.06 & 0.84 & 0.83 \\
\hline 212.77×10_4(0.2) & 543 & 47 & 1.12 & 0.64 & 0.86 \\
\hline $212.77 \times 10 \_4(0.4)$ & 1086 & 28 & 1.09 & 0.71 & 0.72 \\
\hline 212.77×10_4 (0.6) & 1630 & 21 & 1.14 & 0.77 & 0.73 \\
\hline \multicolumn{3}{|l|}{ Average } & 1.18 & 0.81 & 0.96 \\
\hline \multicolumn{3}{|l|}{ Standard deviation } & 0.30 & 0.10 & 0.18 \\
\hline
\end{tabular}


Table 7. Comparison of numerical simulation (NS) results with existing design guidance, for CFEHS columns

\begin{tabular}{|c|c|c|c|c|c|}
\hline \multirow{2}{*}{$\begin{array}{c}\text { Specimen } \\
\text { designation }\end{array}$} & \multirow[b]{2}{*}{$\begin{array}{c}N \\
(\mathbf{k N})\end{array}$} & \multirow[b]{2}{*}{$\begin{array}{l}\text { FRR } \\
(\mathrm{min})\end{array}$} & \multicolumn{3}{|c|}{ Buckling resistance at critical temperature } \\
\hline & & & $\mathrm{EC4}(1) / \mathrm{NS}$ & $\mathrm{EC4}(2) / \mathrm{NS}$ & $\mathrm{EC4}(\mathrm{NF}) / \mathrm{NS}$ \\
\hline $150 \times 75 \times 5 \_1(0.2)$ & 146 & 33 & 1.14 & 0.91 & 1.09 \\
\hline $150 \times 75 \times 5 \_1(0.4)$ & 293 & 22 & 1.12 & 0.93 & 1.09 \\
\hline $150 \times 75 \times 5 \_1(0.6)$ & 439 & 17 & 1.15 & 0.97 & 0.94 \\
\hline $150 \times 75 \times 5 \_2(0.2)$ & 136 & 22 & 1.81 & 1.02 & 1.42 \\
\hline $150 \times 75 \times 5 \_2(0.4)$ & 272 & 15 & 1.78 & 1.04 & 1.14 \\
\hline $150 \times 75 \times 5 \_2(0.6)$ & 407 & 10 & 1.50 & 0.96 & 0.97 \\
\hline $150 \times 75 \times 5 \_3(0.2)$ & 119 & 19 & 1.90 & 0.84 & 1.17 \\
\hline $150 \times 75 \times 5 \_3(0.4)$ & 237 & 13 & 1.68 & 0.76 & 0.86 \\
\hline $150 \times 75 \times 5 \_3(0.6)$ & 356 & 7 & 1.37 & 0.68 & 0.75 \\
\hline $150 \times 75 \times 5 \_4(0.2)$ & 93 & 19 & 1.64 & 0.65 & 0.91 \\
\hline $150 \times 75 \times 5 \_4(0.4)$ & 185 & 13 & 1.51 & 0.60 & 0.67 \\
\hline $150 \times 75 \times 5 \_4(0.6)$ & 278 & 7 & 1.26 & 0.54 & 0.59 \\
\hline $300 \times 150 \times 10 \_1(0.2)$ & 594 & 70 & 0.84 & 0.77 & - \\
\hline $300 \times 150 \times 10 \_1(0.4)$ & 1188 & 36 & 0.95 & 0.87 & 0.98 \\
\hline $300 \times 150 \times 10 \_1(0.6)$ & 1782 & 26 & 1.00 & 0.93 & 0.87 \\
\hline $300 \times 150 \times 10 \_2(0.2)$ & 585 & 54 & 1.03 & 0.82 & 0.92 \\
\hline $300 \times 150 \times 10 \_2(0.4)$ & 1171 & 31 & 1.04 & 0.83 & 0.89 \\
\hline $300 \times 150 \times 10 \_2(0.6)$ & 1756 & 24 & 1.04 & 0.85 & 0.81 \\
\hline $300 \times 150 \times 10 \_3(0.2)$ & 566 & 40 & 1.38 & 0.84 & 0.78 \\
\hline $300 \times 150 \times 10 \_3(0.4)$ & 1132 & 25 & 1.34 & 0.88 & 0.74 \\
\hline $300 \times 150 \times 10 \_3(0.6)$ & 1699 & 20 & 1.26 & 0.87 & 0.68 \\
\hline $300 \times 150 \times 10 \_4(0.2)$ & 543 & 28 & 1.98 & 1.01 & 0.64 \\
\hline $300 \times 150 \times 10 \_4(0.4)$ & 1086 & 20 & 1.75 & 0.98 & 0.71 \\
\hline $300 \times 150 \times 10 \_4(0.6)$ & 1630 & 14 & 1.50 & 0.89 & 0.67 \\
\hline \multicolumn{3}{|l|}{ Average } & 1.37 & 0.85 & $\mathbf{0 . 8 8}$ \\
\hline \multicolumn{3}{|l|}{ Standard deviation } & $\mathbf{0 . 3 3}$ & 0.13 & 0.20 \\
\hline
\end{tabular}




\section{LIST OF FIGURE CAPTIONS}

Fig. 1. Three-dimensional finite element model for CFEHS stub columns.

Fig. 2. Comparison of experimental and numerical results with different steel tube meshes, 150×75×4_C30.

Fig. 3. Comparison of experimental and numerical results with different friction coefficients, $150 \times 75 \times 4 \_$C 30 .

Fig. 4. Comparison of experimental and numerical results, for $150 \times 75 \times 4 \mathrm{~mm}$ columns.

Fig. 5. Different failure modes obtained from the FEA of the stub columns.

Fig. 6. Three-dimensional finite element model for slender CFEHS columns in fire.

Fig. 7. Deformed shape after fire exposure, $300 \times 150 \times 12.5 \mathrm{~mm}, L=2 \mathrm{~m}, \mu=0.2$.

Fig. 8. Axial displacement versus time curves.

Fig. 9. Effect of the non-dimensional slenderness on the fire resistance rating of the columns.

Fig. 10. Effect of the load level on the fire resistance rating of the columns.

Fig. 11. Effect of the cross-sectional slenderness on the fire resistance rating of the columns.

Fig. 12. Effect of the section factor on the fire resistance rating of the columns.

Fig. 13. Comparison of the cross-sectional temperature field between CFCHS $219.95 \times 10$ $\mathrm{mm}$ and CFEHS $300 \times 150 \times 10 \mathrm{~mm}$, after 90 minutes of fire exposure.

Fig. 14. Comparison of the cross-sectional temperature evolution between circular and elliptical columns for different exposure times.

Fig. 15. Comparison between elliptical and circular columns for different lengths and load levels.

Fig. 16. Comparison of the cross-sectional temperature evolution between an elliptical and its bound circular columns after 90 minutes of fire exposure

Fig. 17. Comparison between EN 1994-1-2 simple calculation model and numerical model, for CFCHS columns.

Fig. 18. Comparison between EN 1994-1-2 simple calculation model and numerical model, for CFEHS columns.

Fig. 19. Comparison of numerical results with EN 1993-1-1 buckling curve "c" (relative slenderness computed with coefficients equal to unity). 
Espinos A, Gardner L, Romero ML, Hospitaler A. Fire behaviour of concrete filled elliptical steel columns. Thin-Walled Struct. 2011;49:239-55. doi: 10.1016/j.tws.2010.10.008

Fig. 20. Comparison of numerical results with EN 1993-1-1 buckling curve "c" (relative slenderness computed with French National Annex coefficients). 


\section{LIST OF TABLE CAPTIONS}

Table 1. List of room temperature CFEHS stub columns analysed in this research

Table 2. Measured and predicted maximum axial loads

Table 3. List of CFEHS columns exposed to fire analysed in this research

Table 4. List of CFCHS columns exposed to fire analysed in this research

Table 5. Values of coefficient $\varphi_{a, \theta}$ according to the French National Annex to EN 1994-1$2[39]$

Table 6. Comparison of numerical simulation (NS) results with existing design guidance, for CFCHS columns

Table 7. Comparison of numerical simulation (NS) results with existing design guidance, for CFEHS columns 